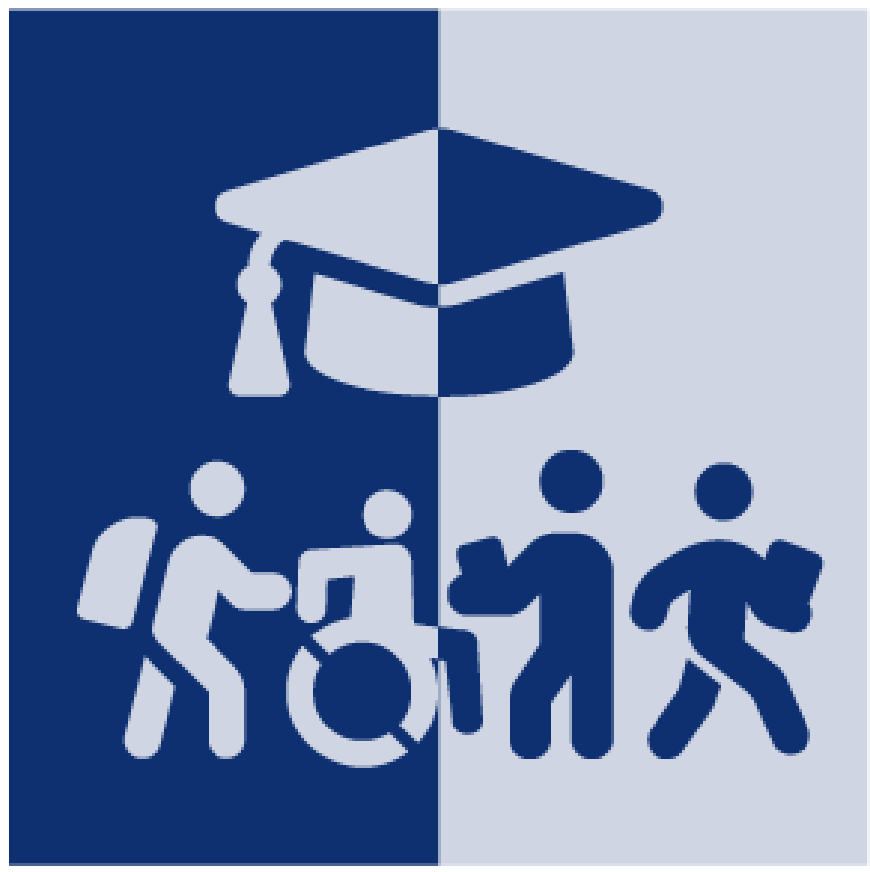

\title{
Campus Culture and Communication at the University of Michigan
}

\author{
A Report Developed for and Supported by the \\ U-M President's Commission on Carbon Neutrality \\ Revised July 6, 2020
}

\section{Creators}

Samer Ali, Faculty Co-Lead

Joseph Trumpey, Faculty Co-Lead

Megan Czerwinski

Benjamin Ingall

Lisa Maillard

Christopher Merchant

Madeline Peery

Contributors

Jude Boudon 
Copyright (C) 2021 by the Regents of the University of Michigan

Some rights reserved

\section{(c) (i) $(9)$}

This work is licensed under the Creative Commons Attribution-NonCommercial-NoDerivatives 4.0 International License. To view a copy of this license, visit http://creativecommons.org/licenses/by-nc-nd/4.0/ or send a letter to Creative Commons, PO Box 1866, Mountain View, California, 94042, USA.

Published in the United States of America by Michigan Publishing

DOI: http://doi.org/10.3998/mpub.12092670

ISBN 978-1-60785-686-3 (open access)

This publication is a result of work sponsored by the University of Michigan (U-M) President's Commission on Carbon Neutrality (PCCN) to inform the PCCN's final recommendations to U-M President Mark Schlissel. This publication does not reflect Commission-level recommendations, and should not be interpreted as being recommendations of the PCCN nor carrying its endorsement. 


\section{CONTENTS}

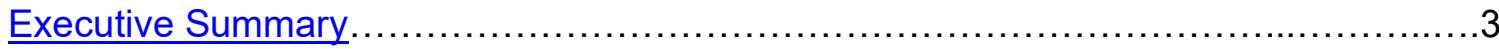

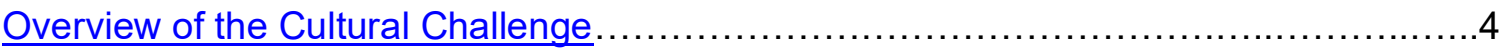

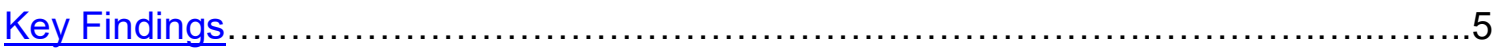

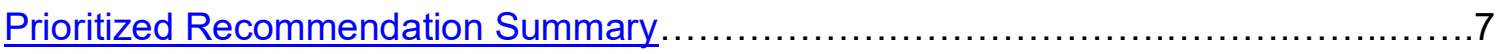

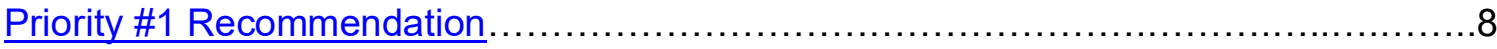

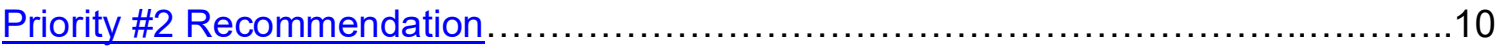

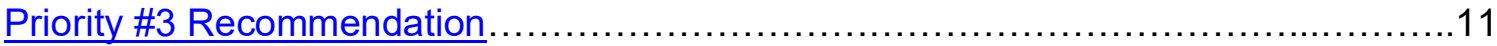

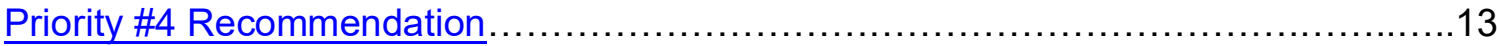

\section{Appendices}

Appendix A: Graphic Novella: A Vision of a Carbon Neutral University of Michigan .....15

Appendix B: Core Cultural Values and Campus Carbon Neutrality Corps.................32

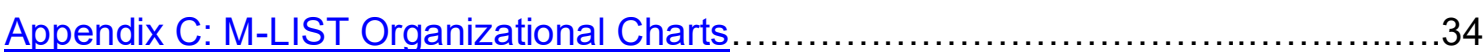

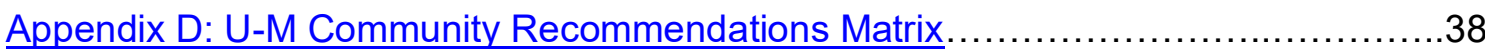

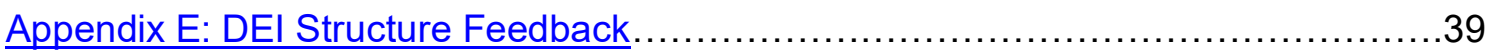

Appendix F: Student Sustainability Literary and Competence Pathway $\ldots \ldots \ldots \ldots \ldots \ldots . \ldots 1$

Appendix G: Sustainability Competencies and Course Integration $\ldots \ldots \ldots \ldots \ldots \ldots \ldots \ldots . \ldots 2$

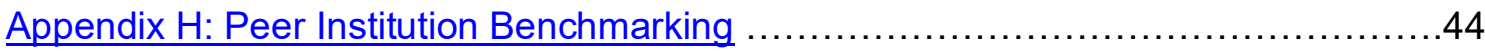

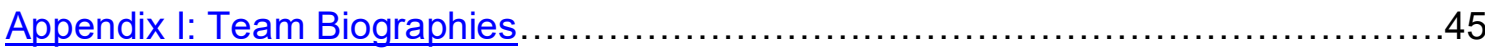

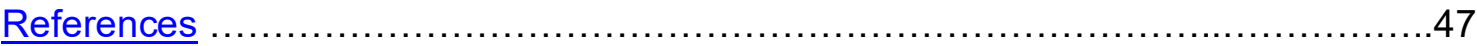




\section{EXECUTIVE SUMMARY}

The Campus Culture and Communication Internal Analysis Team recommends the creation of a fully engaged campus community where every U-M citizen-whether student, faculty, staff, alumni, patient, or visitor-understands the science and significance of global climate change, sees clearly our commitment to carbon neutrality $(\mathrm{CN})$, and participates meaningfully in decarbonization. Many peer institutions have led the way with carbon neutrality pledges and timelines, but there remains a unique opportunity for $\mathrm{U}-\mathrm{M}$ to become Leaders and Best.

Minimizing our carbon footprint is the right thing to do, and lackluster action exacts a cost in reputation and moral standing. But as President Mark Schlissel has factually stated in his public comments, U-M's share of global emissions is comparatively small. So why do we persist? Tipping points are nonlinear. Small actions add up. Decarbonizing a large, complex R1 institution will create a compelling example of how to transition to greater sustainability. That is no small thing. Our course correction would change the cultural fabric of our campus, the region, and the broad swath of Maize \& Blue culture.

The defining challenges of our time, from war to famine to pandemic, have climate change as a common denominator. Just as we embraced social justice as part of our educational mission, so too can we reject dread or denial and embrace the opportunity to live our core values. Like writing and public speaking, sustainability competencies must be recast as citizenship skills for a hopeful future. This is an opening for $U-M$ to leapfrog to the front of the pack. Our report proposes to meet the demands of the global citizenry and workforce while addressing stubborn social inequities that climate change exacerbates.

We acknowledge the complex challenges of achieving carbon neutrality across the three scopes of emissions from all three large campuses and a huge medical center. Creating a technical plan is critical for success and has been much of the focus of other internal analysis teams (IATs). We fully support those efforts and focus on how culture can enable those plans by engaging our citizens. Our carbon footprint is the result of our extractive practices associated with normalized contemporary culture. How do we change the status quo? How do we empower individuals? How can education around wicked problems cascade throughout a diverse institution and broader society? The challenge is not to mitigate bad behavior but to build a regenerative Anthropocene allowing new paths to well-being.

We know that this radical revision of our normal practices will not and cannot happen by accident. Christiana Figueres, an architect of the 2015 Paris Agreement and recent U-M speaker, writes of creating a "Garden of Intention." Indeed, it is only through well-planned design that we can change the very way we interact with the world. This is our chance! This is our opportunity to transform our failing "business as usual" into a beautiful, optimistic vision. We must choose the regenerative path and show the world what that path looks like. We must commit new resources to support our citizens. We need robust top-down leadership with strong support for risk-taking, bottom-up adaptation, and innovation. Building on the institutional success of our U-M Diversity, Equity \& Inclusion (DEI) initiative, our priority recommendations are:

1. An immersive Living Learning Lab experience on campus to shape Maize \& Blue culture;

2. A leadership office, M-LIST, at the Vice President and Provost levels;

3. Sustainability Literacy and Competencies for all staff, students, faculty, alumni, and visitors; and

4. Options to decarbonize investments. 


\section{FINAL REPORT}

\section{Overview of the Cultural Challenge}

In 2011, U-M announced a series of sustainability goals for 2025. With five years remaining, we have seen movement in the right direction, but many goals remain out of reach. The meta-level problem of culture change persists. This IAT was tasked with evaluating and recommending strategies to drive climate change awareness, interest, and investment among all U-M community members, leading to positive behaviors and $\mathrm{CO}_{2}$ reductions. Our mandate builds on decades of thought and labor at U-M concerning sustainability culture, most recently the 2015 Report on Sustainability Culture, which in turn moved the needle beyond the 2010-2011 Campus Sustainability Integrated Assessment. Prior initiatives to assess and drive culture change have perpetuated unintended disparities in the prioritization of sustainability competency that mirror wider gaps in our society.

Our myths of progress are predicated on exploitation in the present at the expense of the future, and regenerative models are the exception not the norm. At U-M, School for Environment and Sustainability students and other early adopters, on the one hand, have access to high-quality sustainability education that prepares them for the demands of system thinking and problem-solving pertinent not only to climate change but also to a variety of complex real-world problems. They develop the skills to creatively counter cultural norms that disadvantage future generations, largely due to cognitive barriers ranging from numbness to mistrust of news to "technosalvation" (Giffords 2011). On the other hand, many more Wolverines continue to labor under an extractive model that replicates the assumptions, causes, and effects that make avoidance and inaction likely. The culture initiatives proposed are mostly behaviorist - "clean your room" or "eat your peas" sort of messaging - to prod largely mechanical routines without creative analysis for yet unimagined problem-solving.

This IAT seeks to reframe the problem of campus culture: U-M is in the business of education. We as educators have a professional mandate to contemplate the future and prepare students. In the 2018 Sustainability Culture Indicators Program (SCIP) report, only $15 \%$ of students indicate taking "a U-M course that addressed sustainability" (Marans et al. 2018). Only $19 \%$ of the respondents to the Planet Blue Ambassadors program survey were undergraduates (Jones and Spillman 2020). What if we conceived of sustainability competencies, developed by Wiek et al. (2011) as basic citizenship skills, like writing or public speaking, promoted across the campus? (See Recommendations 1 and 3 .)

There are challenges specific to U-M's organizational complexity. Our systems have many layers and interlocking parts: some carbon emissions fall under the purview of central management, such as fleets, buildings, power plants, and purchased electricity (scopes 1 and 2 emissions), whereas others rely on individual choices within structured environments, such as energy, waste, food choices (scope 3), and yet others cut across campus and operations, such building standards, biosequestration, planned growth. The Campus Culture and Communication IAT found that the magnitude and complexity of $\mathrm{U}-\mathrm{M}$ and its carbon goals require positive changes not only in individual behavior but also in unit and central culture. (See

Recommendation 2.)

Lesser challenges at U-M are acknowledged and addressed below: 1) sustainability work at U-M has largely been centered in the natural sciences, for several valid reasons, but full engagement in sustainability will require us to leverage the expertise and intellectual investment of diverse disciplines across schools and colleges, particularly the arts and humanities. (See Recommendations 1 and 2.) 2) Over the past decades, U-M-commissioned studies and initiatives have yielded an impressive array of initiatives, like Zero Waste athletics events and Planet Blue, all focused on sustainability. While this demonstrates growing momentum in 
knowledge, will, and action, these efforts are siloed and ad hoc, potentially leading to a sense of futility. (See Recommendation 2.)

The challenges at U-M converge and intersect with challenges in the United States and the world, where human society and employment opportunities increasingly demand a new kind of citizenry and workforce, fully competent to lead in sustainability work with critical thinking and problem-solving skills. A rigorous education can move students from novice sustainability habits to leadership and innovation (Appendices $E$ and F). In fact, even stubborn fossil fuel interests are beginning to sound the clarion call (Greenfield and Watts 2020). In this report, we counsel a paradigm shift and reframe sustainability competence in the context of a well-rounded U-M education. "Sustainability is the collective willingness and ability of a society to reach or maintain its viability, vitality, and integrity over long periods of time, while allowing other societies to reach or maintain their own viability, vitality, and integrity" (Wiek et al. 2015, 241). The psychological and cultural barriers to sustainability stem from old paradigms of how we think of time, fellow humans, and nature and our stubborn racialized history and habits of extraction. The challenges ahead require us to reconsider how we educate and prepare citizens for that future.

The recommendations we make are not a blueprint or regiment, but they do offer a common underlying theme. Unlike prior sustainability culture reports, we reframe sustainability competencies as basic citizenship skills, like writing and public speaking. Unlike, say, accounting or dentistry, sustainability competencies can potentially integrate across the curriculum, especially in the era of a pandemic, and dovetail with ongoing intellectual conversations in the humanities and social sciences about systems and network thinking (Carlson 2020). Given the needs and challenges of the planet, humanity, and the workforce, U$M$ has a moral-reputational imperative to reflect as an institution on how to align activity with core values. As an intellectual community dedicated to knowledge and education, we have an unparalleled opportunity to innovate and foster human potential to meet those pressing needs.

\section{Key Findings: Conceptual and Concrete}

Sources: The IAT participated in over 30 meetings and events to generate data and welcome community engagement, collaboration, and stakeholder feedback on sustainability challenges, resources, constraints, and potential ideas. We sought to set a comparative benchmarking for U-M and peer institution sustainability practices using the Association for the Advancement of Sustainability in Higher Education (AASHE) Benchmarking Tool (2020) and self-generating data. We also reviewed pertinent research, published and unpublished, and a succession of U$\mathrm{M}$ studies, surveys, and reports from the past decade focusing on U-M culture, behavior, and attitudes referenced throughout and listed in the bibliography. We reached the following conclusions:

1. Seeds: U-M initiatives have escalated decisively since 2009 , with several presidentiallevel committees, panels, and studies that signal a deep concern about the climate crisis and thought about the institution's contributions, both positive and negative. Past initiatives have focused primarily on "seeding" sustainability research and education, such as the Sustainable Living Experience (SLE 2020), the Office of Campus Sustainability, waste bins, Zero Waste athletic events, transforming the School of Natural Resources and Environment into the School for Environment and Sustainability (SEAS) in 2017, among others. The pace of initiatives suggests a mounting transgenerational momentum to catch up with peer institutions. However, the siloed presentation of initiatives to the average UM citizen suggests the need for a new phase of U-M leadership, integration, and a coordinated vision.

2. Cultural IIIs: Benchmarking of peer institutions has shown U-M to be on par, but not leading, in most areas of sustainability, and in the area of culture change, nearly every institution faces challenges largely because they are not immune from the dysfunctions of broader society. Several major universities have committed to CN goals (see 
Appendix H: Peer Institution Benchmarking), and many others have committed to increasing sustainability visibility on campus. This has been achieved through solar panels, green roofs, student-led gardens on campus, and real-time energy monitoring in major buildings. Sustainability thinking is still an exception in a world replete of extractive practices. The challenge magnitude of confronting extractive modes with regenerative ones is not unlike that which U-M faces in countering the legacy of segregation, sexism, classism, and other social ills with bold, innovative education of the public for the benefit of society and the world. In effect, U-M has a window of opportunity to lead in culture change and set a new standard.

3. Equal Access to Opportunity: A divide exists between those who have acquired higher order sustainability competencies, through formal or informal learning, and those who have not. In American culture as a whole, extractive approaches are the norm, and sustainability thinking remains an exception. Moreover, as U-M strives toward its equity and diversity recruitment aims, we also recruit self-same underrepresented communities who are disproportionately impacted by the ravages of extractive thought and practice. In this context, U-M has an opportunity to leverage its mission of public education to promote equal access to the kind of sustainability competencies that enable underrepresented communities to analyze, innovate, and problem solve in response to local and existential challenges. Rather than telling students what to do, sustainability competencies teach them how to think and analyze in their particular context: the pros and cons of compostable tableware vs. washing, the comparative advantages of wind vs. solar energy, and various types of battery technology.

4. Sustainability Education at the Core: Considering the local and existential challenges, U$M$ educators have ample cause to embrace sustainability competencies as citizenship skills. While there will always be room for the specialist knowledge producers, the institution needs a minimum level of sustainability education integrated across the curriculum as required courses or as distribution requirements like Race \& Ethnicity. Moreover, the Planet Blue Ambassadors Survey suggests a need for education, even among faculty and staff, about sustainability, not just "recycling is cool" messages (Jones et al. 2020).

5. Workforce and Citizenship Needs: In town halls and other engagement events, students expressed concern about the reckless proliferation of misinformation in our society and concurrent absence of minimum sustainability literacy in courses. They also perceive a lifelong demand for sustainability competencies for citizenship and the workforce in order to face local and existential challenges. Initial reports about corporate trends support this perception (Governance and Accountability Institute 2019). It would be useful for further research (such as the next SCIP) to document and track how students perceive demand and for the U-M Graham Sustainability Institute or SEAS to track workforce needs. Such data could inform discussions by U-M educators surrounding minimum sustainability competencies for all.

6. DEI Model: The complexity structure and culture change at U-M has become evident as we address the legacy of racism and segregation in higher education with DEI in recruitment, mentoring, retention, and inclusion practices. Likewise, with sustainability culture change, we need an integrated and comprehensive U-M model that gives agency and place for everyone. The model needs to be 1) cooperative and collaborative and 2) both top-down and bottom-up, thus avoiding unproductive dichotomies between "admin and the people," which is best embodied in the DEI model. We sought to understand the constraints and potential of DEI as a model in order to transfer DEI lessons and insight to the realm of sustainability culture change. We note its effectiveness in aligning cultural practices with values and for setting a moral vision for the global U-M community and achieving moral-reputational goals among peer institutions. Moreover, DEI strikes a 
delicate balance between centralized leadership, on the one hand, and organic ideas and behavior, on the other. To be sure, our team's conceptual framework diverges slightly from that informing the DEI model. The quantitative nature of the carbon bottom line positions us to integrate benchmarking of metrics to assess carbon reductions while gauging the participation of on-campus stakeholders, namely the 75,000 U-M faculty, staff, and students. Below we also propose a suite of metrics and integrate them into our recommendations.

7. Interdisciplinary and Multi-Methods Pedagogy: At the heart of our recommendations lies sustainability education, which demands equally innovative approaches to sustainability pedagogy outside the usual walls of our disciplinary and methodological boxes. We thus think of our pedagogy as nonpartisan, layered, and multi-methods with the bottom line of pragmatic effectiveness. Our model of education envisions a place for everyone from the novice to the expert to grow toward leadership and innovation (see Appendix F: Sustainability Competencies).

8. Metrics and Reevaluation: Performance data will need to drive the reevaluation process to enable timely analysis and course correction. We propose a suite of metrics. In the context of a true-costs-of-carbon, U-M significantly offsets the costs with savings in persistent domains, such as food, energy, and travel. But the question then becomes how to track and correlate costs, consumption, and behavior. Positive Impact Points (PIPs) and Local Currency provide a key tool: not only does the system offer a reward currency to motivate green choices, but it can also provide behavior data. PIPs data in conjunction with self-reporting and purchasing receipts (say, for high-carbon foods or energy)-along with consumption savings-offers the capacity to triangulate true and comprehensive impact. Moreover, we propose using and expanding metrics of culture such as the biennial Sustainability Culture Indicators Program (SCIP), a longitudinal survey begun in 2012, and the U-M Planet Blue Ambassadors Program Annual Feedback Survey.

\section{Carbon Footprint and Accounting}

The work of this team is conceptual, supporting that of fellow IATs. The carbon footprint of "culture" is indivisible from food, energy, commuting, and waste behaviors. For example, Big House football is a cultural event that no doubt has a large carbon footprint. But the component parts of this footprint are based in food, transportation, energy, etc. Therefore, we largely defer to the carbon accounting of other teams.

We sought data from peer institutions regarding carbon and budgetary savings directly related to culture and behavior change. We were unable to find any published data. Stanford presented unpublished data at the 2019 AASHE conference regarding dormitory energy savings from behavior change. Stanford deployed a group of students to go door-to-door in all dorms before holiday breaks, asking students to unplug appliances, adjust thermostats, and close windows. They reported significant energy savings in the order of $20 \%$ of the year of the intervention compared to the prior year's energy data. The food team was able to quantify savings related to vegetarian, small plate, and trayless dining. There is an opportunity for U-M to track our behavioral data, develop best practices, and publish results.

\section{Prioritized Recommendations Summary}

Since our work is conceptual, supporting that of fellow IATs, we defer to their carbon and cost accounting. That said, we prioritized recommendations based on the following:

1. Cultural Impact: Immediate for students from the first semester onward and long-term benefits (indeed hope) for society upon their graduation and job placement. Creating an 
engaging and educational campus culture also sets a high bar for staff, faculty, and our many visitors. Education, action, and transferability are impact goals.

2. Scalability - the Carbon Reduction Multiplier Effect: Immediate and long-term emissions reductions as tens of thousands of students, faculty, staff, and visitors over several years gain deep and critical understanding of sustainability to support the concrete efforts of fellow IATs. Rather than simply pushing habits, initiatives foster intellectual capacities for the nation and the world.

3. Equity and Justice: As U-M recruits diversity to counter the pernicious legacy of racism and segregation, we have a chance to increase equal access to opportunity by promoting sustainability competencies, conceived in this report as basic citizenship skills needed to analyze, innovate, and problem solve moving forward.

4. Transferability: Each recommendation can be replicated and modified at comparable institutions of higher learning, helping to enhance the signature reputation and moral standing of U-M.

5. Financial Considerations: Only recommendation 2 poses considerable new costs. The first and third recommendations are "hardwired" into the U-M core educational mission. They would entail adjustments to existing practices, with financial implications in line with customary increases in educational costs.

\section{Priority \#1 Recommendation: Shape U-M into a Carbon Neutrality Living Learning Lab}

Shaping campus as a Carbon Neutrality Living Learning Lab prioritizes the fullest purpose of $\mathrm{CN}$. The interaction, acceptance, and growth of the $\mathrm{CN}$ goals will be carefully managed, but we must promote growth and innovation beyond the balanced spreadsheet of $\mathrm{CN}$. We must strategically plan to support the diverse ways we create a new vision of the University. We must foster a new mindset in which every citizen understands the actions we take. This unique amalgamation must be integrated into educational, research, and experiential opportunities. This integration includes new synergies across faculty, staff, student, and the public. CN will touch every aspect of life on campus, and embracing a living learning lab mentality opens the door to discovery. This is our opportunity to not only regenerate the campus but also foster new beauty, new connections, and new insight and facilitate the spread of CN culture. This is our opportunity to walk the talk and create a unique U-M story. (See Appendix A: Graphic Novella, the story of a possible scenario of two first-year undergraduates in the near future.)

These opportunities will not happen all at once over the entire campus. There will be early adopters and pilot programs that showcase and highlight concepts and progress. The Michigan Leadership and Innovation for Sustainable Transitions (M-LIST) Office will rely on existing sustainability assets as early adopters to build cultural momentum. The Diag, the Grove, the Union, the League, and the Big House should all be high priority for early actions. High-visibility aspects of Dearborn and Flint campuses should also be targeted for early adoption. Benchmarks for success must include visibility, equity, accessibility, didactic support, and beauty. For example, if we invest in a distant renewable energy project, a mirrored and similar installation needs to be local and accessible. There should also be limited access at the distant site. Projects early in our $\mathrm{CN}$ quest should tackle relevant, high-profile cultural events on campus. For example, what does a "no waste" football game look like? What does a carbon neutral football game look like? Offsets for individual travel, team travel, the blimp? Tree planting on the day before? Volunteers washing durable goods of stadium cups and plates? We can make it happen.

During town hall meetings, students shared their deep concern about the future and expressed a need for expanded opportunities to learn formally (in class and lab) and informally (residential experiences, lectures, co-curricular, cafés, online). $\mathrm{CN}$ and sustainable culture must permeate and cut across all aspects of the university (see Appendix B: Core Values). 
1. Immersion Learning: Like language immersion, sustainability skills as a "language" need to be used daily in the ambient environment. We learn our cultural values of respect, curiosity, and discovery because we see and practice them daily on campus. Places like the Campus Farm, the Sustainable Living Experience, Planet Blue, UMSFP, and others require ongoing support, coordination, and expansion with the help of M-LIST. Many projects, including routine $\mathrm{CN}$ maintenance and $\mathrm{CN}$ events, could be spearheaded and expanded by a volunteer corps-the Campus Carbon Neutrality Corps (CCNC). The CCNC can clear snow from PV panels, use manual mowers to cut the grass of the Grove, tend a flock of sheep on the Diag, and create overall buzz and support for CN missions by leading discussions and education about $\mathrm{CN}$ and campus actions. (See Appendix B: CCNC logo.)

2. User Experience Design: Through intentional, well-planned design we can change the very way we interact with the world. This is our opportunity to transform "business as usual" into a beautiful, optimistic vision. A recent PBSIF grant funded design concepts for a sustainable living-learning/leadership complex. The innovative complex of buildings would be carbon positive, providing coop-style housing in close conjunction with the Campus Farm at the Matthaei Botanical Gardens. It could be home to sustainability leaders, Student Sustainability Initiative, Planet Blue Student Leaders, and the Sustainable Living Experience, etc., U-M citizens planting new treescapes and oncampus food forests, classes building and deploying bike rack shelters, etc. Colored lighting on the Burton tower, the Big House, and Angell Hall columns could convey messaging about the current state of energy use on campus or progress toward shortand long-term carbon goals. U-M can design virtual and physical spaces and products that increase the likelihood of positive behaviors with useful, usable, and desirable features that work intuitively and provide an inherent action reward loop that is sustainable. These actions should be bold and visible to send a signal about institutional values and priorities.

3. The Positive Impact Points (PIPs) Program: This program leverages gaming psychology to encourage sustainable behaviors. This cannot be an end in itself, but it can help move a newbie to novice level or a novice to the intermediate (see Appendix F). In a broader culture of sustainability, these behavioral incentives can make formal classroom learning relevant as students begin to understand complex and critical thinking and analyze for themselves and in their future contexts. The PIPs pilot is slated to begin in Fall 2020. A well-aligned Local Currency focused solely on CN behavior could be used to fight difficult problems such as travel during campus breaks. Myriad students could take charge of developing and deploying an actual currency, such as creating carbon pricing and labels on common items and actions for campus, values, trading rates, design, etc. A scenario shared in the graphic novella (see Appendix A) has students earning this currency to purchase tickets to a sought-after concert hosted during the week of spring break. Tipping points are nonlinear. Small actions will add up to significant impact.

4. Nudges: Our decisions and spaces can create paths to sustainability. Campus menus can prioritize and reward plant-forward choices and limit access to beef and other high carbon items. We can preserve an opt-out alternative for communications, but default communications from the university/unit/department would be paper, including departmental letters to faculty. Some decisions can simply be made by M-LIST (see Recommendation 2), such as requiring all U-M paper purchases to be FSC certified or supplying data or description of normative behavior to influence behavior while leaving the negative choice cheap and easy. There are well-known pros and cons: the extent of a nudge's impact varies considerably depending on contexts and the complexity of human decision-making, but they are small, easy, and inexpensive to implement. 
5. Transparency and Communication: All CN efforts need to be openly shared and publicly accessible: that is, coffee cup wars will be irrelevant if the long-term plans for the power plant are not clear.

6. Highlighting $\mathrm{CN}$ Using the Arts: Reinforcing campus culture change will benefit by utilizing existing arts programming to highlight a U-M CN mission and to create themes that tie into new academic course requirements. UMS is open to this concept, as are UMMA, SMTD, Stamps, and other arts-related groups both on and off campus. Related concepts are included in the inventory (see \#7 below).

7. Full Inventory of Ideas Large and Small: We maintained a full, categorized inventory of all concepts presented to us. The inventory could be of use for new leadership and teams. (See Appendix D: U-M Community Recommendations Matrix.)

\section{Priority \#2 Recommendation: Create the Michigan Leadership and Innovation for Sustainable Transitions (M-LIST) Office}

We recommend the creation of a new, high-level office that promotes Leadership, strongly supports Innovation, and manages and facilitates our institutional transition to more environmentally sustainable practices. The office is led by two complementary positions, one in the Office of the Provost as Vice Provost and the other in the Office of the President as Vice President. They will operate jointly to co-chair the M-LIST Office. M-List's unique position ensures that sustainability is incorporated into academic and budgetary affairs (Vice Provost) as well as other critical university activities (Vice President). The scale of the work, the immense breadth of the work, demands a skill set that is too broad for a single person. They will require support from, and manage, a broad cohort of Unit-Specific Sustainability Officers who are tasked with unit-specific carbon goals. M-LIST is tasked with being the unifying, official voice for the U-M sustainability mission. Currently, there are many sustainability voices diffused across many units and all lack a high-level administrator that provides mission clarity. As we have experienced with our DEI initiative, bureaucracy can be minimized while providing high-level support, clarity, and accountability. M-LIST will create and drive the vision, coordinate, communicate, elevate, institutionalize, and prioritize all campus-wide sustainability initiatives. MList will set the mission and act as the organizer and synergist between current sustainability entities on campus. Importantly, they are tasked with setting short-term and long-term goals while managing the specifics of reaching Carbon Neutrality. See Appendix C for proposed MLIST organizational charts. Hiring criteria for the new positions must include experience in facilitating institutional change. The office could utilize theories of change such as the Change Wheel: Elements of Systemic Change (Kanter 2011) from Harvard and the Deming Cycle (plando-check-adjust), which has been effectively used for Bosch's CN commitment (Kanter 2011).

M-LIST must facilitate innovation and develop an appetite for risk. The leadership should set priorities and develop requests for proposal (RFPs) for projects that cut across our culture. For example, U-M could re-invent the annual meeting. We all have experience now in a COVID-19 world with virtual meetings. Can we innovate and develop a virtual substitute for in-person conference travel that covers not just plenary sessions but also socializing, networking, poster sessions, gallery viewing, etc. Can we institute policy that cuts across tenure and promotion reviews that honors these kinds of low-carbon dissemination?

Top-Down Mission Support: M-LIST's funding mechanism should function similarly to the Office of DEI such that schools, support offices, faculty, staff, and students can submit funding applications for initiatives developed by the community. Based on our interviews, it is clear that a single unified mission will be helpful to all sustainability units. M-LIST determines which initiatives best align with the $\mathrm{CN}$ vision of the university or the goals of the related offices (OCS, 
Graham, Planet Blue, etc.) and supports these initiatives. This model has helped to facilitate growth in the DEl initiatives at the university and has been embraced by many programs at the university (see Appendix E: DEI Structure Feedback).

Bottom-Up Idea Support: We recommend a bottom-up proposal system to support the ideas of community members, schools, and support offices in developing innovation. This leaves room for diversity of thought, equal access by underrepresented communities, and agility in moving our culture toward $\mathrm{CN}$ and sustainability norms, thought, and identity. This flexibility is vital in reducing resistance to this program and allowing for the cultural adoption of sustainability and the University's CN goals. It also allows for increased community engagement and input regarding the direction of the University's decision-making on these issues. The proposal system would address student concerns voiced in town halls that included a lack of support for grassroots mobilization at the University and a lack of transparency.

External Collaboration: M-LIST will purposefully connect to local and state governmental agencies, regional energy providers, Big-10 sustainability offices, peer institution sustainability offices, regional environmental NGOs, and regional social justice and environmental justice initiatives. This includes CN efforts in Ann Arbor and the state, DTE, Consumers, National Wildlife Federation, Flint, Detroit, and elsewhere. These connections will be critical in creating and sharing new knowledge, including communication, best practices, collaboration, funding support, student projects, co-curricular events, etc.

Unit Council \& Strategic Plans: In order to facilitate grassroots innovation, M-LIST will develop a Council of School and Unit Sustainability Leads. This council should be composed of Sustainability Leads from all units. Working topics will include everything from physical plant infrastructure goals to the required curricula and training for their units. Each lead will be accountable for their unit's CN strategic plan, including carbon accounting and cultural considerations. Some large units, like the Medical System and Athletics, will require full-time Sustainability Officers.

Carbon Neutrality Goals: M-LIST will manage the overall progress of carbon goals. A few concepts are listed in the org chart as well as a placeholder for working groups dealing with scopes 1, 2, and 3 emissions.

Engaging all U-M Citizens: M-LIST work will reach every single U-M citizen-faculty, staff, student, alumni, visitor. They will facilitate both curricular, co-curricular components of $\mathrm{CN}$ as well as operational $\mathrm{CN}$ details with transportation, physical plant, procurement, financial operations, etc.

Financial Burden/Costs: While the outlays are uncertain and depend on the specifics yet to be determined by further conversation with leadership and community engagement, the costs and moral-reputational benefits would be similar to DEI or perhaps greater because of the technical scope reaching into operations and beyond the University.

\section{Priority \#3: Develop Campus-Wide Curriculum, Training, and Literacy in Sustainability}

This report shifts culture change on campus beyond behaviorist terms to ground changes in our educational mission. Recommendations 1 and 2 are both bottom-up and top-down collaborations that integrate efforts to produce synergies, and Recommendation 3 further leverages our educational mission. Based on the SCIP results, the majority of staff, students, and faculty continue to engage at low levels and have comparable levels of competencies. That 
said, the results do indicate that climate change is important to them, many calling for further educational opportunities. The Vice Provost in M-LIST will play a critical role in launching and managing these opportunities across the breadth of the University. The M-LIST office will address the logistical and political feasibility challenges of developing requirements in a manner consistent with U-M values of consensus building. In particular, M-LIST would need to rely on principles and practices of faculty-shared governance to respect academic freedom, ensure intellectual rigor, and achieve sustainability effectiveness that makes sense for the thousands of fields and disciplines. We thus recommend that the M-LIST establish committees devoted specifically to building consensus and developing best practices using an organizational structure similar to the President's Commission on Carbon Neutrality (PCCN) and the IATs for the functions of oversight and focused work. The oversight portion of the structure would draw on distinguished university professors to establish the broad principles of sustainability education, with the five competencies outlined as a starting point, and the working groups would be specific to each school or college. Each committee's membership would need to represent each school or college's full intellectual diversity of fields and disciplines.

The recommendations below include training for students, faculty, and staff in sustainability literacy and competencies:

1. Course Requirement: We recommend a 3-credit required course in $\mathrm{CN}$ and sustainability for all students. We acknowledge the challenges of a 3-credit requirement, but U-M data points to the biggest gains in attitudes and behavior result from enrollment in a semester-long course. Sustainability courses have shown improvements in sustainability awareness and competency among undergraduates of various disciplines (RemingtonDoucette and Musgrove 2015). There is some early evidence that too little exposure to climate science can result in a negative outcome. Recently, Bio 171 has instituted three dedicated lectures on climate change. Surveys, however, indicated that many students became overwhelmed, felt helpless, and said they were overall less likely to engage with climate work following this scant module (Duffy 2020). Comparatively, a full course imparts a holistic understanding of climate challenges and allows students to face personal responses and move toward creative analysis and solutions-based action.

2. Carbon Neutrality \& Sustainability Designation: The Race \& Ethnicity designation certifies courses that fulfill distribution requirements for students and provide an incentive (enrollments) to faculty to develop such courses, intersecting with nearly every field and discipline. That system engages the minds of students and faculty in pressing issues across history and the globe. Based on the model's success and recognition, which has been widely adopted in American higher education, we recommend an analogous process for Sustainability designation. At present, the Graham Sustainability Institute keeps a running list of sustainability-related courses. The faculty who teach these courses can be invited to apply for the formal designation. This allows for a greater diversity of perspectives on sustainability and the best ways to address the climate issue. We recommend that a board develop criteria to evaluate syllabi of the courses that apply for this designation and that the achievement of the Carbon Neutrality and Sustainability designation include funding for participating programs. This is not necessarily feasible in all schools but should be the standard against which other curriculum developed at the university is measured.

3. Modular Curricular Integration: While we recommend $\mathrm{CN}$ and sustainability course requirements for all students, we recognize there will necessarily be variations across disciplines. Professional schools, with strict standards and packed curricula, may struggle to implement a 3-credit distribution requirement. Modular integration of sustainability content may ease the transition. The Gala platform (learngala.com), an open access platform for case-based sustainability learning built at SEAS, is an existing 
curricular tool that may be readily utilized to create and implement interdisciplinary, multimedia modules. A recent study at the U-M School of Nursing found increases in sustainability competence following one Gala case about local water quality, suggesting drastic curricular change is not needed to begin bolstering sustainability competence (Czerwinski 2020). However, care needs to be taken to implement active, problembased, holistic pedagogies to avoid overwhelming students as described above (Golrokhian et al. 2016; Hardin et al. 2016).

4. Orientations: Planet Blue is currently working with Student Life to develop a Canvas training module for the online new student orientation. All new students, faculty, and staff should be required to complete similar online training as part of their orientation. We recommend building on this momentum when we return to in-person orientations by introducing students to the vision of the Living Learning Lab for carbon neutrality and sustainability. Unit-level Sustainability Officers, like DEI leads, will be responsible for ongoing training and education in their units.

5. Professional Development \& Continuing Education: Faculty and staff awareness may be bolstered by requiring and incentivizing completion of the Planet Blue Ambassadors program. While updates may be needed to address new carbon neutrality goals, this resource provides a thorough, action-oriented introduction to sustainability efforts on the Ann Arbor campus. We recommend adapting the program with local details for the U-M Dearborn and U-M Flint campuses. We also recommend promoting alumni and staff continued education through existing initiatives such as Gala sustainability cases and Academic Innovation Coursera MOOCs. This training could be extended through the UM Alumni Association's network, and the Alumni Association voiced interest in participating.

\section{Priority \#4 Recommendation: Decarbonize Investments}

U-M must align its existing financial investments and investment philosophy with its $\mathrm{CN}$ goals. This includes both the endowment and U-M employees' retirement portfolios. As previously stated, to ensure the full engagement from the U-M citizenry, transparent policies that cut across all aspects of carbon at the University will be required. We acknowledge that the PCCN mandate did not include recommendations regarding divestment. We include divestment as an essential part of openly discussing the $\mathrm{CN}$ mission and keeping all citizens engaged and supportive. Put bluntly, there is a growing pattern among peer institution leadership (University of California system, Stanford, Oxford, etc.) to divest; the Association of Big Ten Students and faculty senates across the country (Cornell, Harvard, etc.) are voting to divest. The U-M Faculty Senate is actively discussing a vote of our own. There is plenty of precedent and rationale, including poor financial returns on fossil fuel funds. We did not build a specific bibliography or arguments focused on divestment knowing the President's mandate. We include it as a priority to note the inconsistency of policy and that inconsistency in vision and leadership can undermine the educational mission, impact morale, and harm culture change.

Setting aside endowment policy, there are immediate actions that can be taken with retirement accounts. We reached out to the leadership of the U-M Retirement Savings \& Deferred Compensation Plan to learn about low/no carbon investing options. During the 20182019 fiscal year, almost $\$ 500$ million was invested in U-M TIAA and Fidelity accounts. It is not possible to easily determine what fraction of the new or existing investments are specifically in fossil fuel/high carbon funds.

Steve Sidlinger, Assistant Director, was able to identify specific funds in both TIAA and Fidelity that are low/no carbon. He confirmed the office's willingness to begin offering workshops for employees to immediately access these funds. With time, they could amend their tools and 
training to make investing in these funds more accessible for individuals, advisors, and managers. M-LIST should work with them to make these options happen as soon as possible. Low/no carbon investment funds identified:

- Fidelity Select Environment \& Alternative Energy Portfolio (FSLEX)

- $\quad$ TIAA-CREF Social Choice Low Carbon Equity Fund (TNWCX)

- $\quad$ TIAA-CREF Green Bond Fund (TGRNX)

- $\quad$ TIAA-CREF Short Duration Impact Bond Fund (TSDJX) 
Appendix A: Graphic Novella

\title{
A Vision of a Carbon Neutral University of Michigan
}

\author{
Madeline Peery \& Lisa Maillard \\ Illustration by Jude Boudon \\ President's Commission on Carbon Neutrality \\ Campus Culture and Communication Internal Analysis Team \\ April 2020
}




\section{Preface}

The purpose of this graphic novel is to offer an example of the life of a newly accepted University of Michigan freshman attending a carbon-neutral Michigan and the ways we as an institution can instill principles of sustainability and carbon neutrality into their experience. Our goal as the Campus Culture and Communication Internal Analysis Team is to catalyze visible, embedded, interdisciplinary, and progressive sustainability efforts that help all members of the University of Michigan community become more climate conscious, energy aware, and green all around. This graphic novel does not contain every example possible but rather helps demonstrate how incorporating a living learning lab into the Wolverine experience at the earliest possible stage can help prime our students to these concepts throughout their time at Michigan.

\section{Introduction}

\section{Wolverine Express}

My name is Jeremy, and I'm proud to say that I'm going to be a Wolverine for the next four years of my life, and I'm even more proud to say that I'm the first one in my family to be going to college. On the morning of August 16th, my parents drive me up to Los Angeles to board the Wolverine Express. I have no idea what to expect; I signed up because I thought it would be a great way to meet new people before coming to campus, but all I really know is that the Wolverine Express is a bus that will take us on a trip through the country as we make our way to Ann Arbor and teach us about sustainability as we go.

When we get there, the bus stop is already teeming with students, trailing suitcases behind them and talking amongst themselves. As my parents help me unload the car, butterflies start to swirl in my stomach; I'm nervous to finally be leaving home and starting my new life as a college student, but excited to finally meet my new life-long friends. When everybody's suitcases have been loaded, we board the bus. I choose a seat next to a girl who introduces herself as Sarah, and soon enough, the bus pulls out of the station and we're officially on our way to the University of Michigan!

Once we start onto the highway, a man at the front of the bus stands up and introduces himself as Professor Hoffman, our professor for the next ten days, as well as the rest of the semester. He gives a quick introduction of himself and encourages us to get to know the people we're sitting next to. Sarah tells me that she's interested in Sociology in LSA, and I tell her I'm set on majoring in Computer Science through the College of Engineering. We mingle with the other students around us-I'm thrilled to find out that one boy is in the same computer science lecture as me, and a few other students will also be living in South Quad with me.

\section{Central California Droughts}

At noon, we arrive to the first stop on our weeklong trip: the city of Fresno- - or, to be more accurate, a little vineyard just outside of Fresno, where we are welcomed by the vineyard owner. 
As we munch on some of her home-grown grapes for lunch, she walks us around her property and explains how the changing climate in California has affected the way of life on her vineyard. Rising temperatures makes it harder for many grape varieties to grow, leading to more difficult growing seasons. In addition, she explains, water scarcity has had a large impact on her land. More and more, farmers in the Central Valley are needing to flood their lands in the winter when the rains fill local rivers, to allow this water to trickle down through the water table and replenish a dangerously low supply. The droughts in California over the last few years have made it increasingly difficult for her to rely on surface reservoirs, so she's had to get creative in order to keep her family's business afloat. And, she says, this is only going to get worse with climate change, as the Sierra Nevada's, which are the main source of water for central California, experience less snow in the winter and provide less water to crops as a result.

\section{Northern California Wildfires}

After our day at the vineyard, we drive four hours north to Tehama County. On the way, the small group I've made friends with talk about everything from what we're most excited about for UMich, what we're most nervous about, the student orgs we want to join, and how different college life will be from high school. As we get closer to Tehama County, I notice how the landscape suddenly changes from deep green forests to barren hills filled with charred black trees.

The Wolverine Express rolls up to a local fire station in Tehama County, where we meet several firefighters and a local scientist who's studying the effects that wildfires have on local ecology. The firefighters teach us about the Red Bank fire, which burned over 8,500 acres in Tehama County in 2019. The scientist, a top researcher at UC-Berkeley, explained that wildfires are an essential and natural part in renewing old parts of forests and making room for new organisms to grow, but wildfires at this scale are detrimental for almost every aspect of nature. She explains that wildfires burn all the natural vegetation that native animals eat and use for habitat protection, leaving some species vulnerable not only to predators, but also harms the growth of young. With tens of thousands of trees no longer cleaning the air with photosynthesis, carbon levels in the local atmosphere are increased, which makes the air dirty and can lead to health issues such as asthma. Many areas where wildfires occur take years or decades to recover, which can also have large economic impacts on an area, especially if a big part of the local economy depends on forestry.

\section{Grand Teton National Park}

The third day of our trip is spent driving from California to Wyoming. I'm really enjoying getting to know my new friends and seeing the landscapes across so many states that I've never been to before. When we drive past the mountain range of the Grand Tetons, I can't keep my jaw from falling open; it's one of the most beautiful things I've ever seen. My family never traveled 
much when I was growing up, so this is the first National Park I've been to. What an amazing sight!

After parking the Wolverine Express, we're met by a Park Ranger who takes us for a short three mile hike, and explains the geology and history of the Grand Tetons, and tells us the story of how President Teddy Roosevelt created the National Park System to preserve natural public lands.

About a mile into our trip, we spot a group of bison grazing in the distance. There seems to be a calf in the mix, standing close to its mother, and I am so excited when I point it out to my new friends. According to the Park Ranger, the calf was probably born in late April or early May, and it will take him about five years to reach his full height. He then tells us about all the different kinds of animals in the park and how scientists can study animals in national parks to measure how animals and ecosystems are changed by human intervention.

Once we've finished our hike and had a chance to take in the sights, we sit down for a picnic lunch at a campsite and the Ranger changes the topic of discussion to something a little less fun than adorable baby animals. He tells us that a lot of national park employees are concerned by the possibility of Grand Teton being damaged by corporate drilling and infrastructure projects that are in the works with the current Presidential administration. According to him, species like pronghorn and mule deer are threatened by these developments, as their migration routes are catastrophically impeded by gas pads and drilling rigs. Despite these migration corridors being federally protected, the encroachment of fossil fuel projects has somehow gone unnoticed by the Bureau of Land Management and Wyoming Game and Fish Department. It isn't enough to simply allow these animals to live, he says. We must also make an effort to preserve their means of existence.

\section{North Dakota Access Pipeline}

I am interested in seeing the North Dakota Access Pipeline the most, because in high school I read a lot about the protests in the news and on social media. When I was younger I didn't know much about it and the effects that the pipeline would have on the native communities that lived on those public lands. I'm eager to find out exactly what the source of resistance is, and the threat this pipeline represents to the communities who would be most impacted by it. It takes us a full day to arrive at Cannon Ball, North Dakota, where the DAPL protests first gained media attention in 2016. When we arrive, we are greeted by one of the Standing Rock Sioux tribal members who participated in the fight to block this pipeline. She explains that her tribe is passionate in its fight against this project for several reasons: not only would the pipeline be operating on sacred Standing Rock Sioux lands, but there are genuine concerns within native communities beyond the Sioux, including the Crow and Lakota tribes, that it will contaminate their water supply from the Missouri River. This coming together of tribes is a monumental moment, she says, as even historic enemies like the Lakota and Crow tribes have put aside their animosity to fight against this pipeline. 
The bulldozing has made the landscape look ravaged. I can't help but feel furious at the oil companies that take what isn't theirs and poison entire communities without a second thought, just to make more money. When I express my frustration to Sarah and my other friends, they agree. Professor Hoffman and the tribal leader add that it is not just the fossil fuel companies that are to blame: the entire political system is broken, with politicians bending to the will of corporate backers and refusing to pass laws protecting groups such as the Sioux tribe because fossil fuel companies fund their political campaigns. The tribal leader emphasizes the idea that this is racism, and we should fight against injustice even if we aren't personally affected by it. I'm starting to understand what the term environmental justice means - in a just world, people would not be tear-gassed or arrested for trying to keep their drinking water clean. This was the last stop on our trip, I continue to think about what I've seen at Standing Rock as the Wolverine Express continues on.

\section{Ann Arbor-Central Campus}

After a long week and a half, we finally arrive in Ann Arbor. Even though I have loved my time on the Wolverine Express, I am happy to have a permanent place to call home for the next four years. After spending time with other freshmen, I am more excited than ever to be a part of this community full of "leaders and best," and I want to hit the ground running. Sarah and I are basically joined at the hip now; we have the same taste in movies and the same love of terrible dad jokes, and she promised to teach me how to play the ukulele once we got to our dorms. It's nice to have made such a good friend in a short amount of time-it helps make the process of being a college student seem a little less daunting. We all arrange to eat dinner that night as a class to celebrate the end of a great trip.

Immediately, I start to notice things as the Wolverine Express drives by Central Campus - for one thing, it looks like there are sheep (sheep!?) on the Diag. They munch on the grass, unbothered by the people around them, although that might be because the makeshift corrals keep them contained to a particular part of the Diag. I ask Professor Hoffman why there's sheep on the Diag-I definitely don't remember that detail from my prospective student tour. He chuckles and says that this is a greener alternative than using lawn mowers. The sheep do a better job without the need for gasoline, and they don't make all that racket that John Deere landscaping equipment does. As we pass, I make eye contact with one of the sheep for a second, before he returns to his meal. This is a pretty special school, for sure.

The first week of school is called Welcome Week, and the university hosts a ton of events for first-years. Aside from all the cool events, the best thing about welcome week is all the free stuff we get. I get a free water bottle from Planet Blue, along with a free 'Michigan First Gen' sticker to put on my laptop! My new friends and I watch a free screening of a movie at the UMMA, go to a silent disco on the Diag, and with a few of the other kids we met from our dorms, we go to the yearly midnight party at Meijer. Formally called the Meijer Back-to-College event, hundreds of first-years take busses to Meijer to stock up on things for their dorm, meet 
other first-years, and have an evening filled with fun. I buy some organization boxes for my dorm and a bunch of snacks for myself and my roommate, and the cashiers give us free reusable bags with the Michigan logo on them, that we can use whenever we need to run errands.

On the first official weekend of school, I attend my first ever Michigan football game!

The day is searing hot but thankfully they let us bring empty reusable water bottles into the stadium. It must be something they recently decided to do, because all the drinking fountains in the stadium are brand new and there are signs encouraging zero-waste game days. I'm thankful that I'm able to stay hydrated, but not so thankful for the sunburn I get that day.

Over the next few days, little details start to stick out to me. For one, the buses around school are all electric, and having my new reusable water bottle comes in handy because the sale of single-use plastics is banned on campus. This includes coffee cups, which seem like such an integral part of student life, what with all the all-nighters and morning boosts. But it makes me happy to see students in line at Starbucks, personalized thermoses or UMich water bottles in hand, conscientiously helping to reduce the waste our community produces. I've already started to personalize my Planet Blue water bottle with stickers and decals. It takes me a few days to find my way around campus without getting lost, but I notice that every major building has an interactive board which displays energy information such as how many megawatt hours it takes to keep the lights on, how much energy is spent from renewable sources, and what steps the University has taken to increase energy efficiency in that building. Many of the buildings have switched to motion-sensor lights to use at night rather than keeping the lights on, and compostable toilets have become an option in most of the newer buildings on campus. At night, the Burton Memorial Tower is lit up with colorful LEDs, giving a visual read-out of campus energy use for the day. Green means it was lower than the standard set by the PCCN, yellow means it fell a little short but came close, and red means tomorrow will need to be considerably better.

\section{Dorm Life}

South Quad is a place I never could have imagined before I got here. 1,000 students live here, meaning I have virtually an unlimited amount of friends just seconds away from my dorm room. My roommate and I hit it off and decide to form an IM soccer team with my friends from the Wolverine Express. Our RA is a junior named Michael. At our first hall meeting, he gives us the usual spiel about how as our RA he's our friend, not our enemy, and to reach out to him if we ever need anything. He gives us some tips for being around campus (don't feed the sheep human food, make sure you download the bus app so you're never late to your classes on North campus), and to my surprise, gives us some information on how to be more sustainable in the dorms. He explains that since there are so many students living in the dorms, the buildings have to be running 24/7, meaning the lights, heating and cooling, and elevators never turn off. He shows us an app called MEnergy we can download on our phones - if we put in our room numbers, we can see how much energy we're using in our rooms on a daily basis. Michael also 


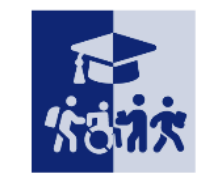

shows us that there are composting bins in the trash closets in our halls, teaches us what can and can't be composted, and explains that washing our laundry on the cold setting helps save energy, too.

\section{Academics}

As a freshman in the engineering school, my classes include Engineering 101, Calculus II, and Econ 101, but my favorite class by far is my sustainability seminar. Twice a week for an hour and a half I get to meet up with the fifteen other students I traveled through the country with, and we discuss things we saw on the trip, environmental policy in the news, how we can be more sustainable in our own lives, and how campus can be more sustainable. Professor Hoffman teaches us about the entire history of sustainability at $U$ of $M$, and how much work was put into creating the PCCN and how those recommendations helped change the university for the better. He takes us on field trips to the campus farm and the Barton Dam, and we have a representative talk to us about the decision to use sheep on the Diag instead of lawn mowers. Our final project, which we have almost a month to work on, asks us to create a proposal for a sustainability project that could be implemented on campus. My group comes up with the idea of creating a rain garden on the Diag to help control flooding on the sidewalks when it rains. Another group comes up with the great idea of installing solar panels on the roof of Ross and Weiser Hall.

Even in my prerequisite courses, we manage to discuss sustainability. In my Econ 101 course we discuss the economics of wind energy versus natural gas through supply and demand, and Sarah tells me about how her SOC 100 class is discussing the social impacts of communities living in polluted cities versus non-polluted cities. Our trip with the Wolverine Express and the examples of sustainability in other classes has really made me realize that the environment is at the forefront of so many aspects of society that I'd never considered before.

\section{Flash Internship}

The first few weeks of freshman year go by incredibly fast-I'm having such a good time here, I barely realize that it's almost fall break! In our sustainability seminar, Sarah tells me she got accepted for a flash internship with the City of Ann Arbor Sustainability Director for fall break. LSA offers flash internships every year for multiple fields, giving students 3 to 4 days to meet professionals in their desired industry, network with like-minded students and alumni, and learn about the different career paths they can take within a specific industry. Sarah explains that her flash internship with the City of Ann Arbor allowed her to meet several city commissioners, scientists, and directors who are all working hard to make Ann Arbor a better place. She got to sit in on meetings with the City of Ann Arbor's Energy Commission, where they discussed the feasibility of putting solar panels on buildings throughout the city in order to decrease the city's greenhouse gas emissions. After hearing her experience, a few classmates and I decide to apply for a flash internship during spring semester. 


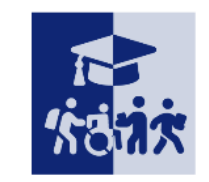

\section{PIPs}

After fall break ends, news spreads around campus that Lizzo will be performing at the spring break concert at Hill Auditorium in March! The university holds an annual spring break concert on campus every year, with dozens of other events going on during the week to encourage students to stay on campus to reduce their emissions instead of flying across the country for spring break. Sarah is two seconds away from exploding with joy when she tells me, and I'm just as excited. Here's the twist: apparently, students won't be able to buy tickets with regular money. Instead, we'll need to accrue a certain amount of Sustainability PIPs (Positive Impact Points) that can then be traded in for a concert ticket.

Students at Michigan, myself included, are given instructions on how to set up the PIPs app the moment they make the decision to come to this University. It allows you to gain PIPs for all sorts of things that help improve our community, planet, and personal health. You can earn them for all kinds of things - shopping at a local farmer's market, taking the bus to school instead of commuting, or attending a meditation course. These PIPs are then redeemed as reallife perks: a certain amount will get you a voucher for class textbook costs, or discounts at local stores, or, in this case, a ticket to see arguably one of our generation's coolest artists.

I find out that a few friends are attending a talk about food security and climate change tomorrow in Angell hall, and that attendance is redeemable in PIPs. I decide to join them-I need to start working toward that concert ticket as quickly as possible! The talk is hosted by the U-M Sustainable Food Program, and we get 100 PIPs points for attending. The Lizzo ticket costs 1,000 PIPs points, so I still have a long way to go, but luckily we have plenty of time. At the end of the talk, the Sustainable Food Program promotes the Maize and Blue Cupboard in the basement of Betsy Barbour, which is a student-run food cupboard that works to increase food accessibility across campus. The day after the talk, I go there to pick up some snacks, and snag 50 more PIPs points, and RSVP to attend a mindful meditation seminar next week for another 100 points. Lizzo, here I come!

\section{End of Semester}

Before I know it, the end of first semester is here. It was undoubtedly the best 4 months of my entire life, and I know that second semester will be even better! Our rain garden project in my sustainability class got an $\mathrm{A}+$, and Professor Hoffman tells us that we should submit our proposal to the M-LIST office, which is in charge of all sustainability initiatives on campus, to see if we can receive funding for a trial version of the project. My group members agree that it would be awesome to see our project come to life on campus, so that's what I will be looking forward to doing when I return to Ann Arbor after winter break!

Because the majority of my sustainability cohort are all from California, we all meet up and ride to the airport together through The Ride, which is a bus system that goes from campus to the Detroit airport. In just one semester, this cohort of fifteen students have become my best friends, and I'm so grateful that we all have the shared experience of having taken the Wolverine 
Express to campus. I feel as though I have really grown throughout the course of this semester: before coming to U-M, I barely knew anything about the importance of sustainability, but after going to a school that cares so much about making our world a greener place, I feel as though I'm well-prepared for any sustainability problem that comes my way. 


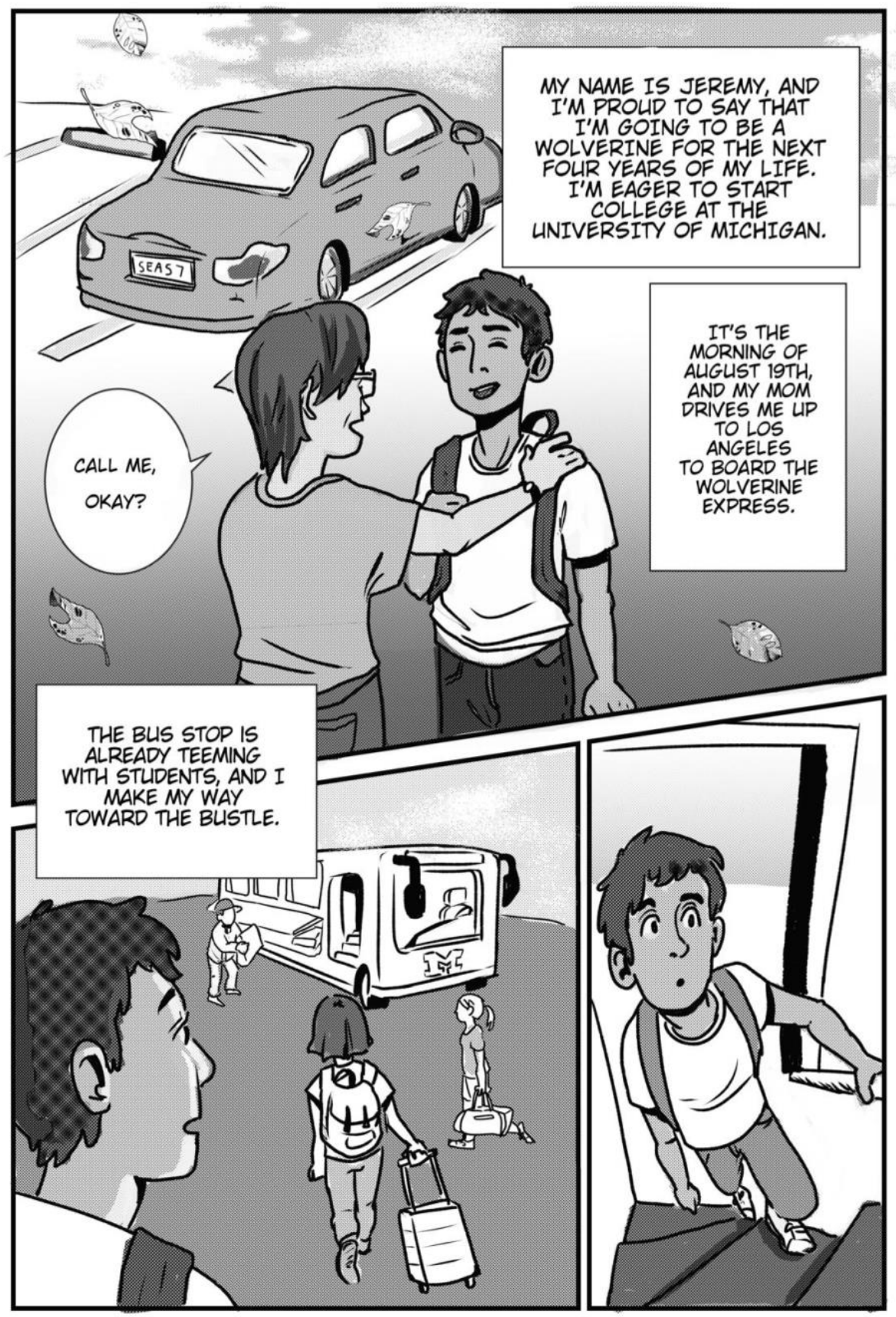



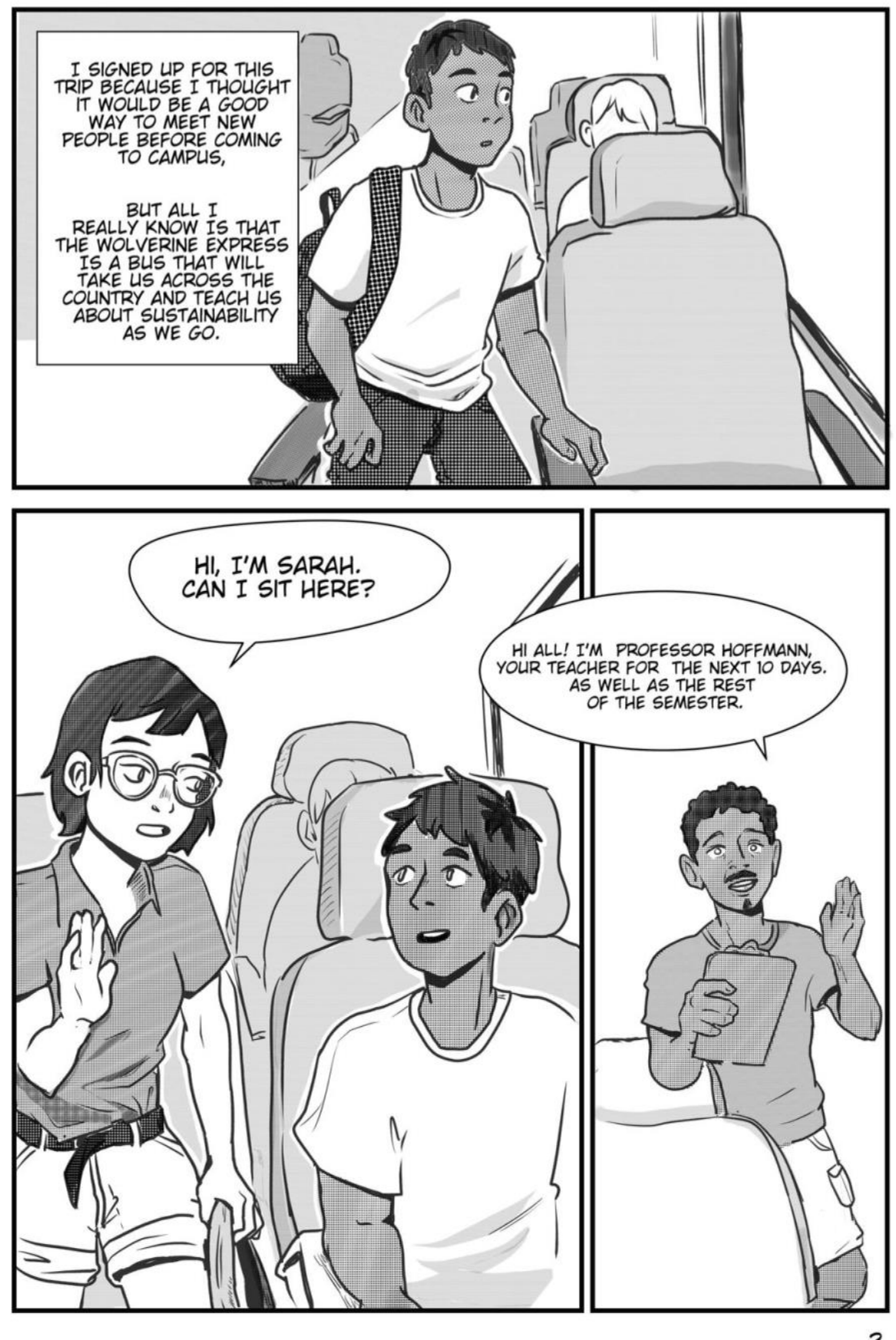

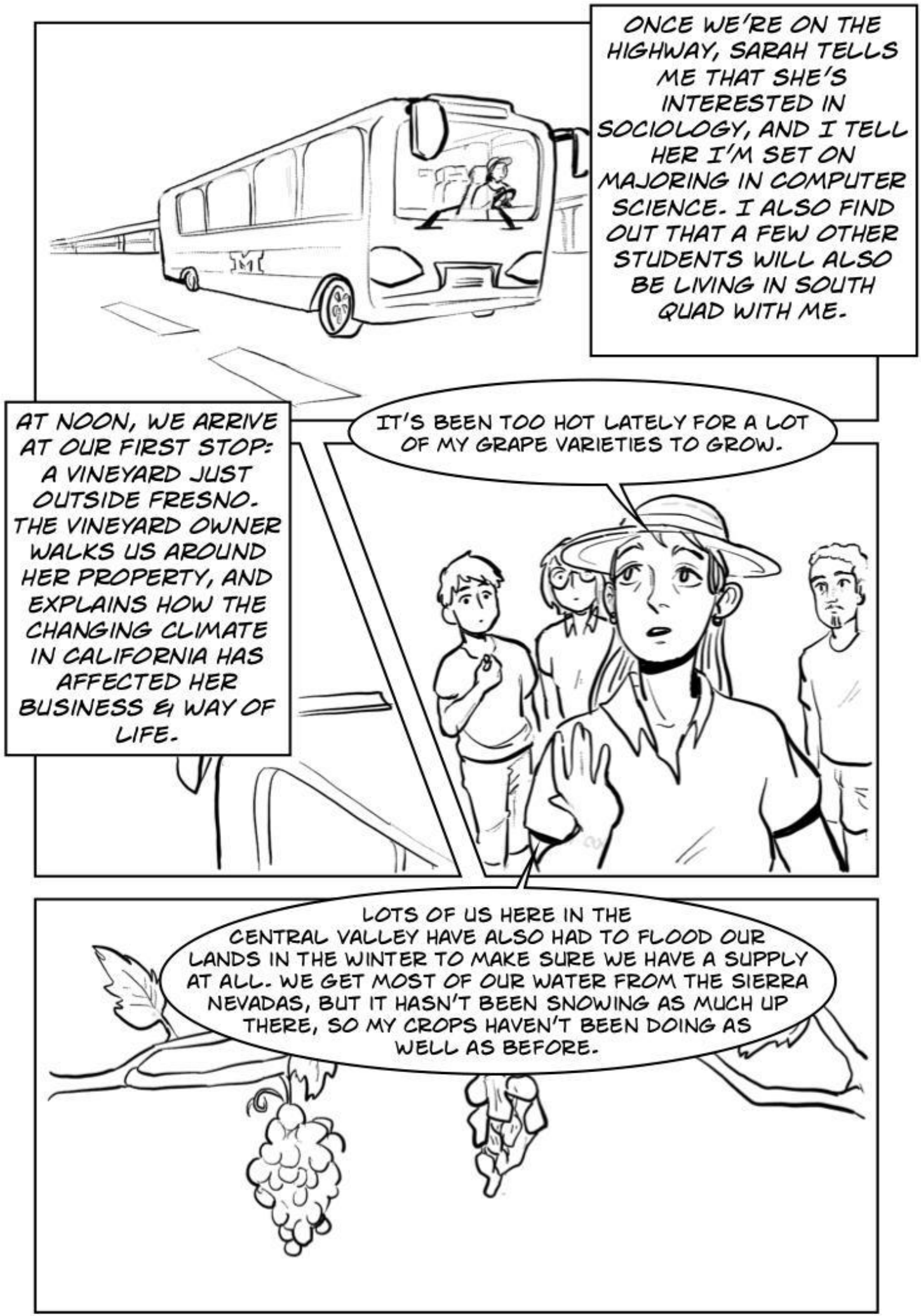
OUR NEXT STOP IS FARTHER NORTH IN TEHAMA

COUNTY, WHERE I NOTICE THAT MUCH OF THE

LANDSCAPE HAS BEEN CHARRED.

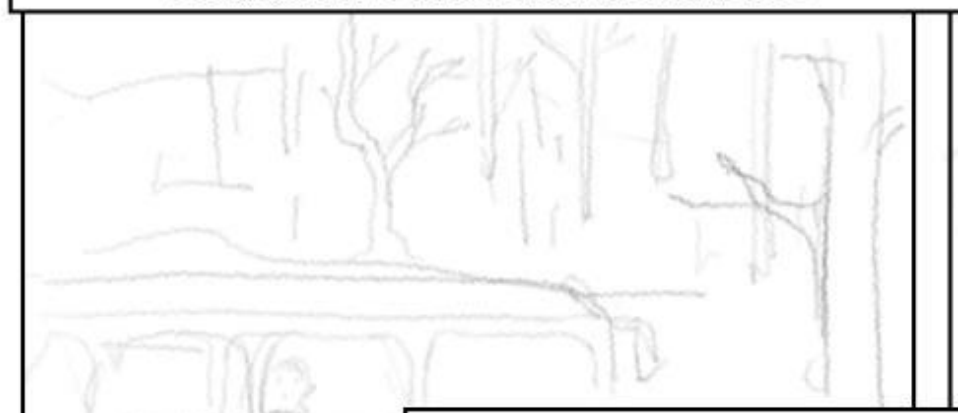

WE ARRIVE AT A FIRE STATION, WHERE WE MEET A FIREFIGHTER AND A LOCAL

SCIENTIST STUDYING THE EFFECTS OF WILDFIRES ON NEARBY ECOLOGY. THEY TELL US ABOUT THE RED BANK FIRE THAT RECENTLY BUIRNED 8,500 ACRES OF LAND IN NORTHERN CALIFORNIA.

WILDFIRES ACTUALLY PLAY AN

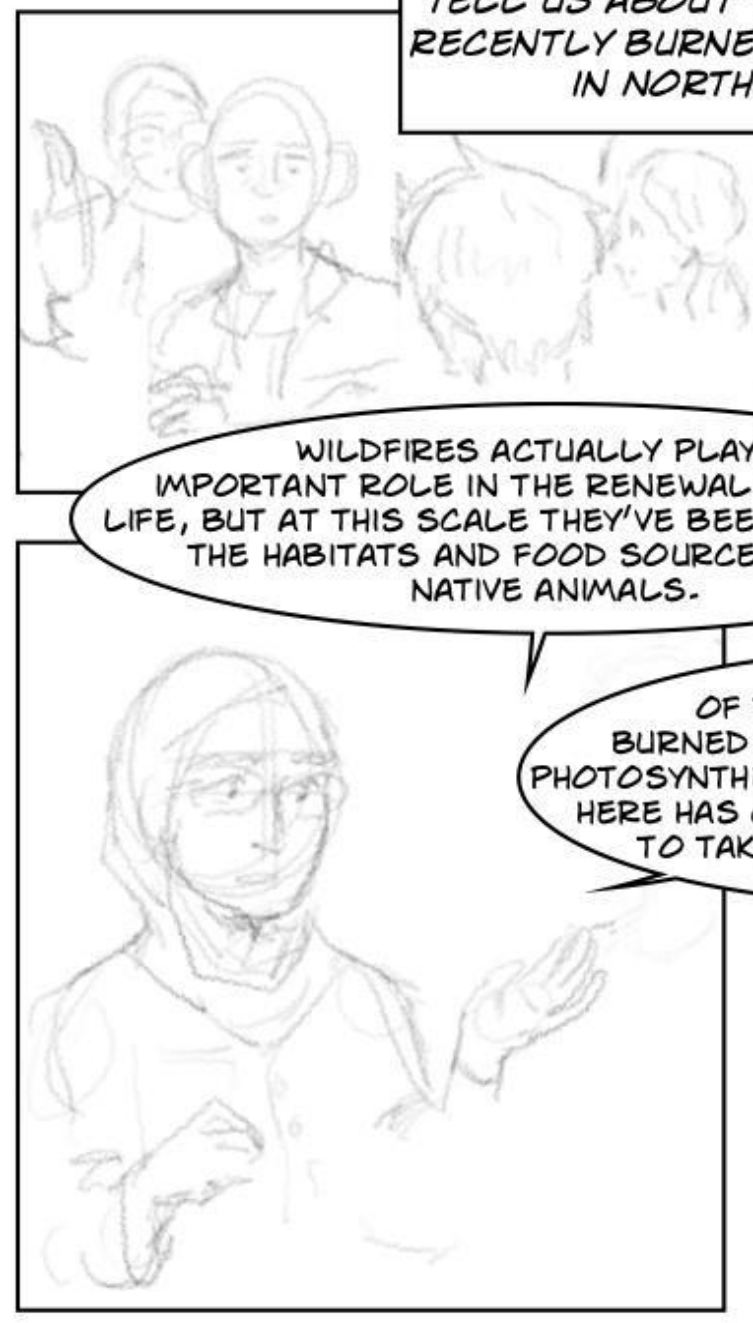
WITH TENS OF THOUSANDS OF TREES BURNED AND A LACK OF PLANTS TO OTOSYNTHESIZE, THE AIR QULLITY AROUND HERE HAS GOTTEN WORSE. IT'S GOING TO TAKE DECADES FOR THIS ALL TO RECOVER. 
THE THIRD DAY OF OUR TRIP IS SPENT GETTING TO WYOMING, AND THE GRAND TETON MOUNTAINS ARE A SIGHT TO BEHOLD.
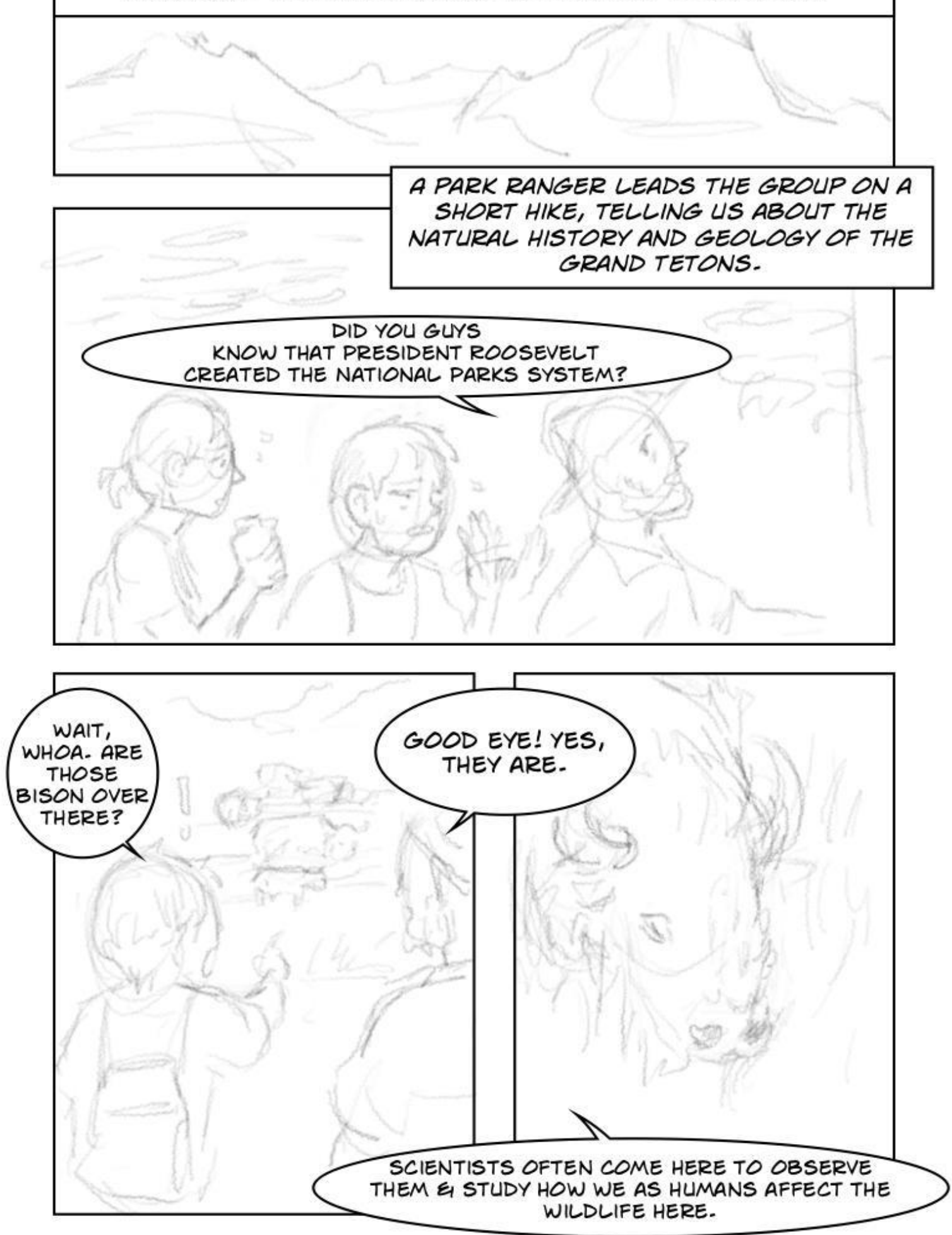

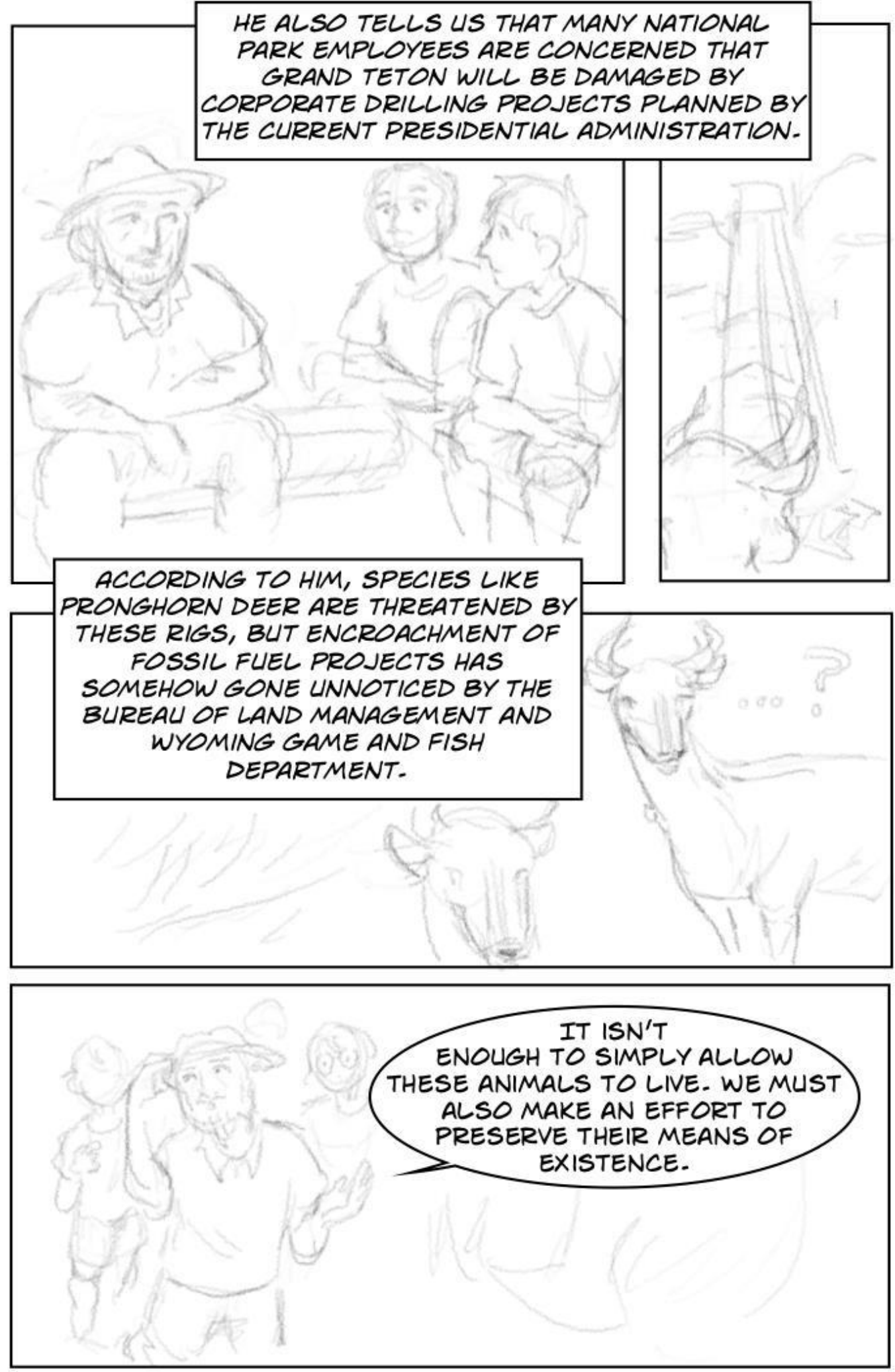
THE NEXT DAY WE HEAD TO THE SITE OF THE NORTH DAKOTA ACCESS PIPELINE. I READ A LOT ABOUT THE PROTESTS IN HIGH SCHOOL. I WANT TO FIND OUT EXACTLY WHAT THE SOURCE OF RESISTANCE IS,

AND THE THREAT THIS PIPELINE REPRESENTS TO THE LOCAL COMMUNITIES.
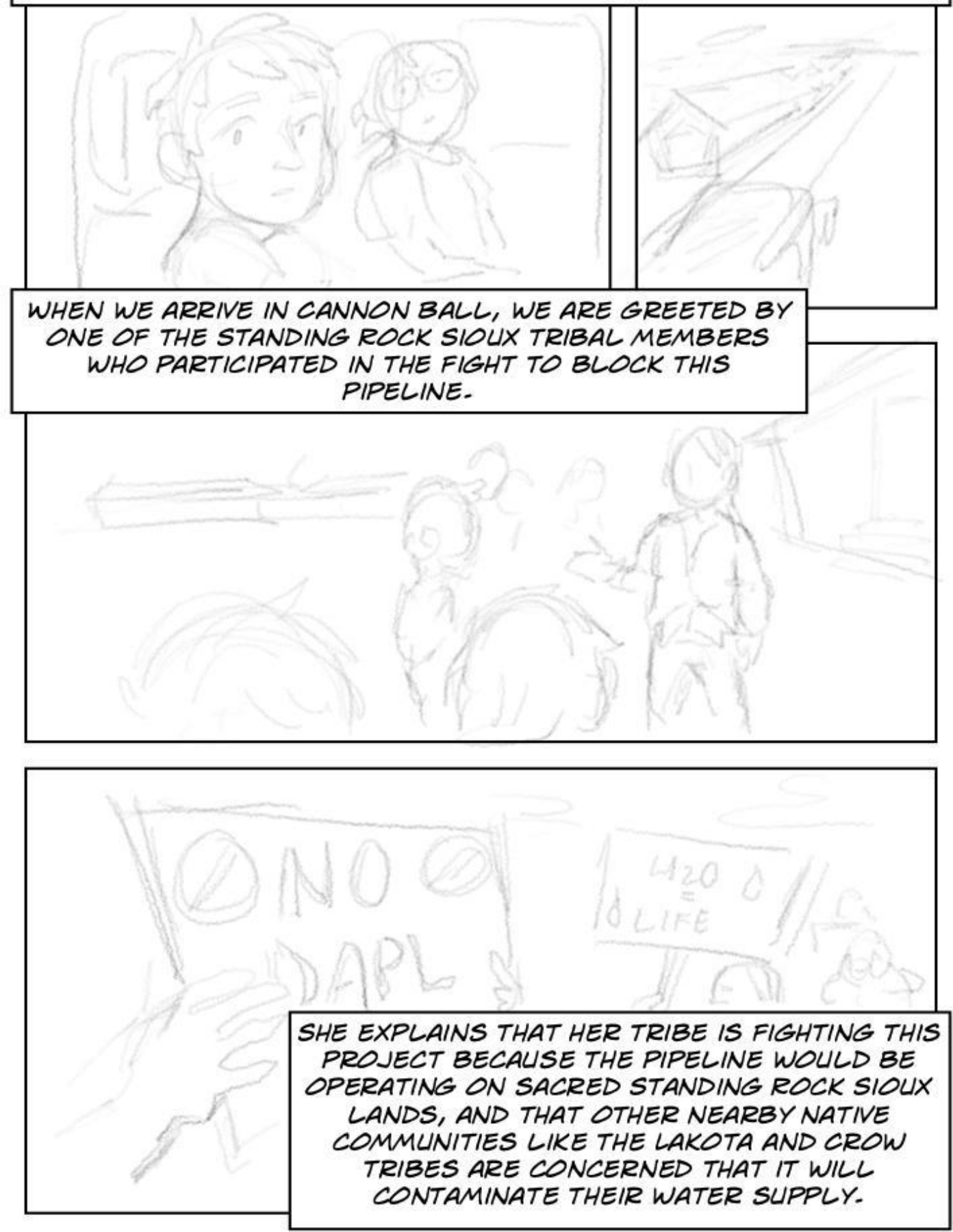
THE BULLDOZING HAS MADE THE LANDSCAPE LOOK RAVAGED.

I CAN'T MMAGINE THE NERVE IT WOULD TAKE TO POISON ENTIRE COMMUNITIES LIKE THIS...

IT'S NOT JUST THE OIL COMPANIES-THE WHOLE POLITICAL SYSTEM IS BROKEN. THE INDUSTRY IS PROFITABLE ENOUGH THAT PEOPLE IN POWER REFUSE TO

PASS LAWS TO PROTECT OUR LAND.

I DON'T THINK PEOPLE SHOULD BE TEAR-GASSED OR ARRESTED FOR TRYING TO KEEP THEIR DRINKING WATER CLEAN.
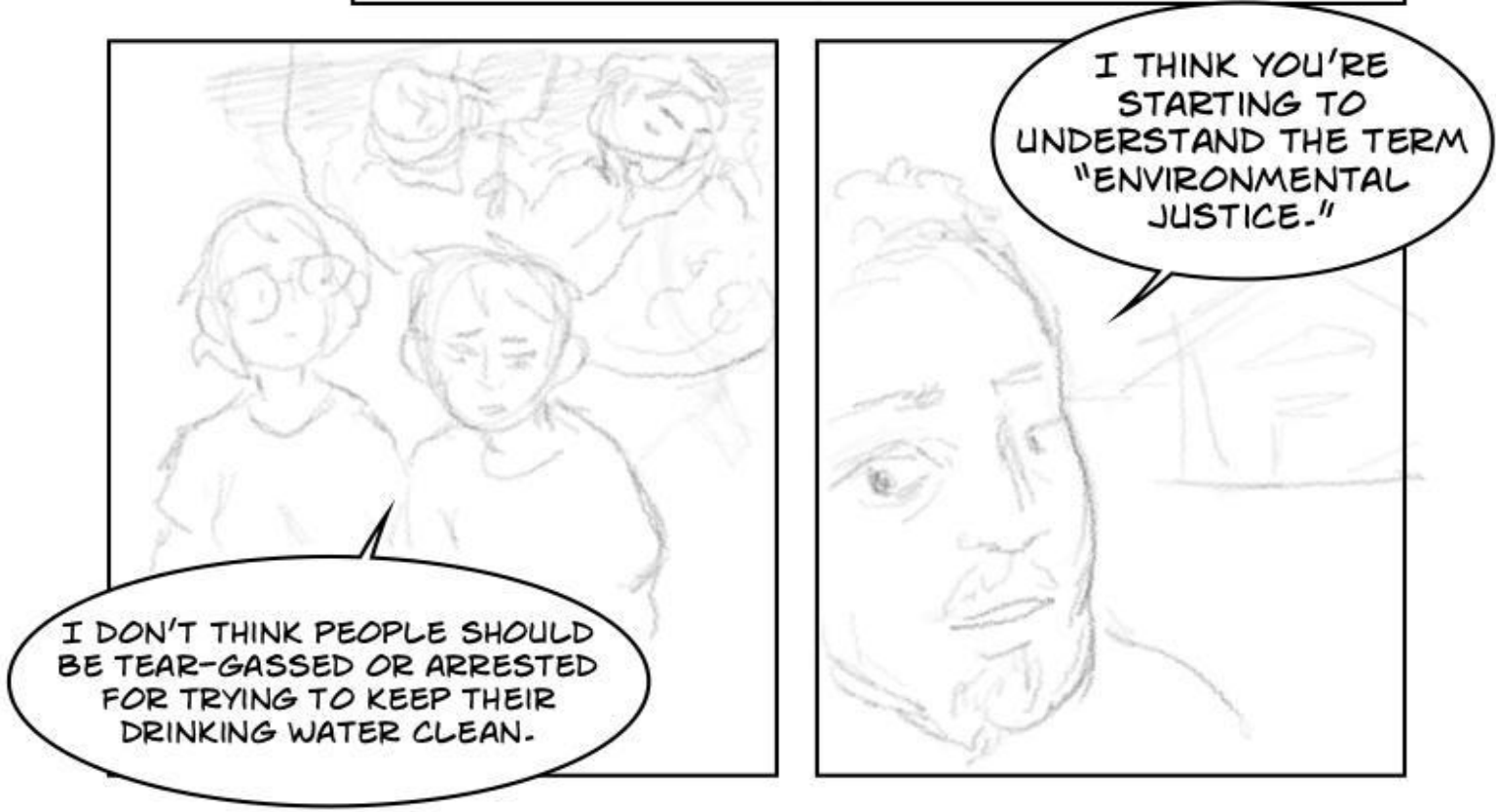
Appendix B: Core Cultural Values and Campus Carbon Neutrality Corps

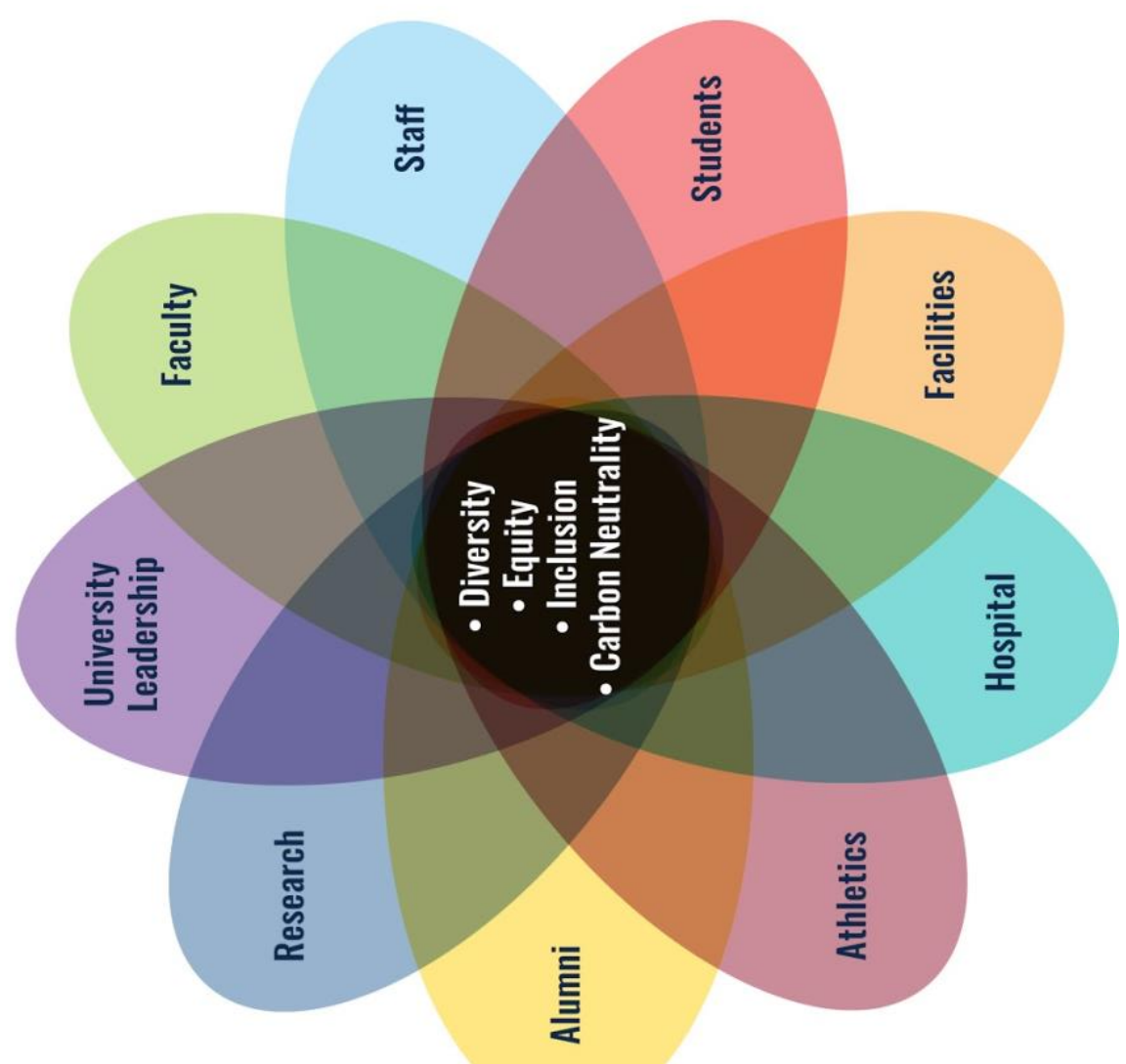

峞 


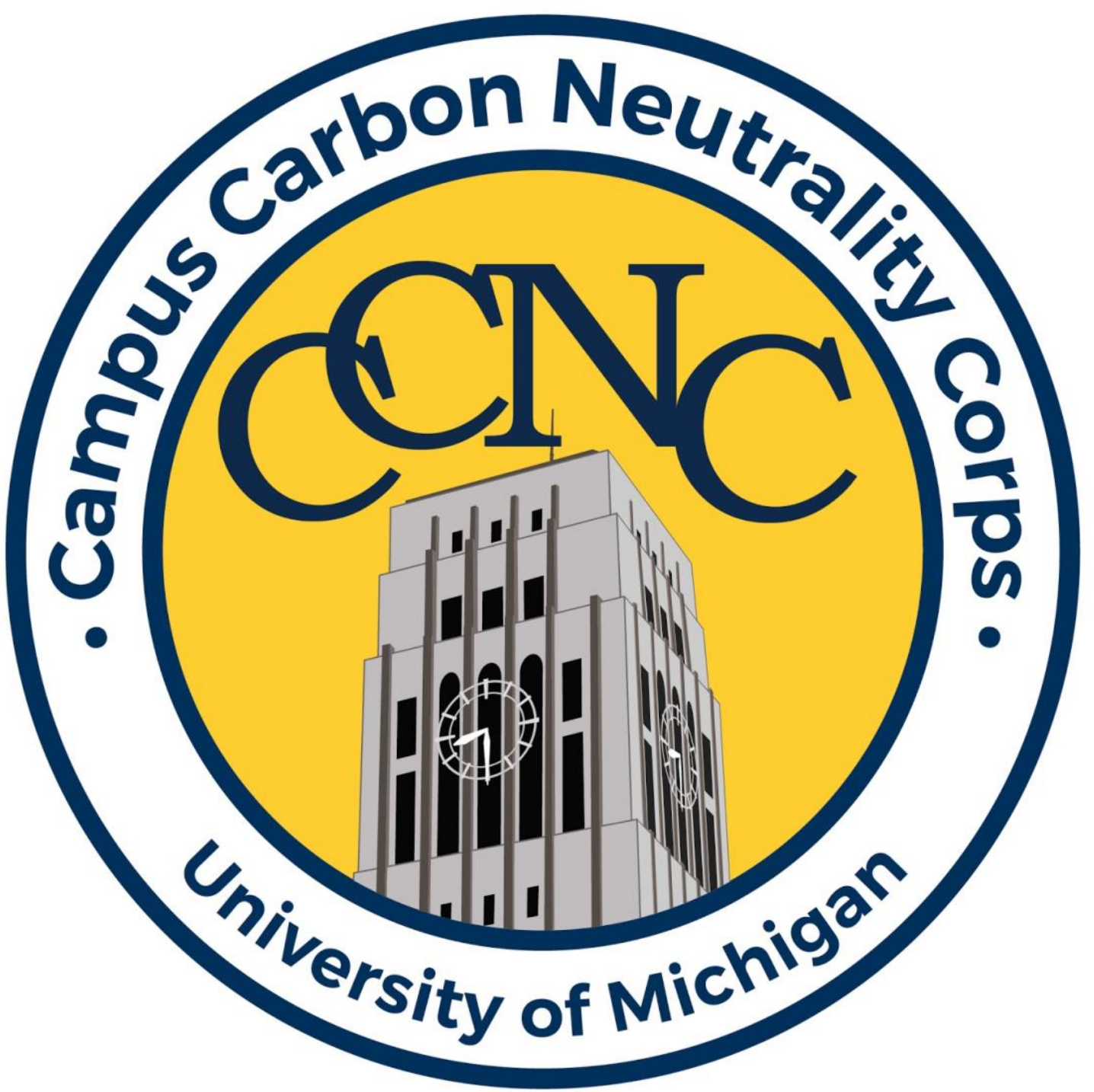




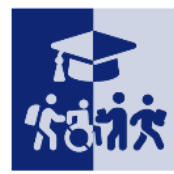

Appendix C: M-LIST Organizational Charts
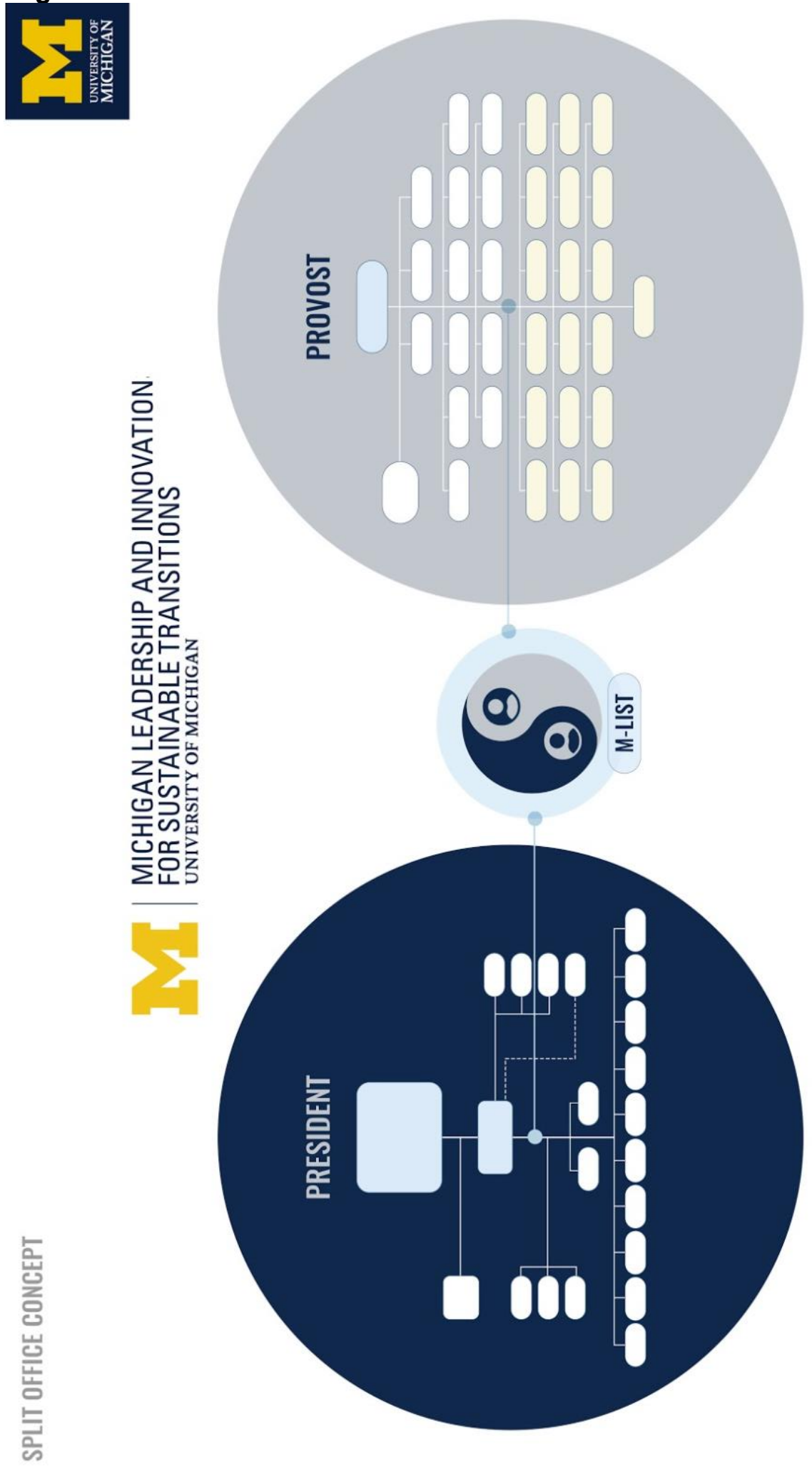


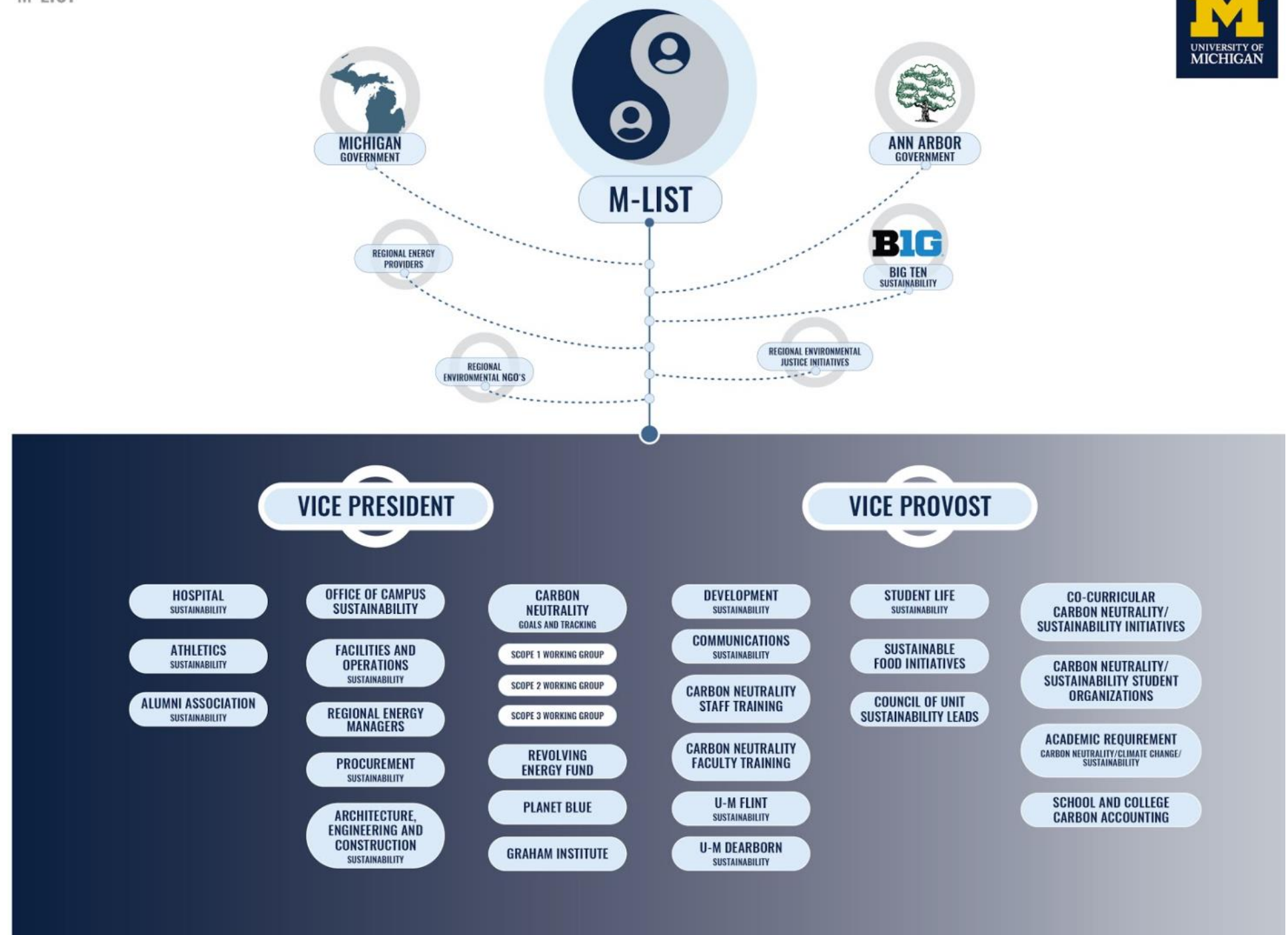




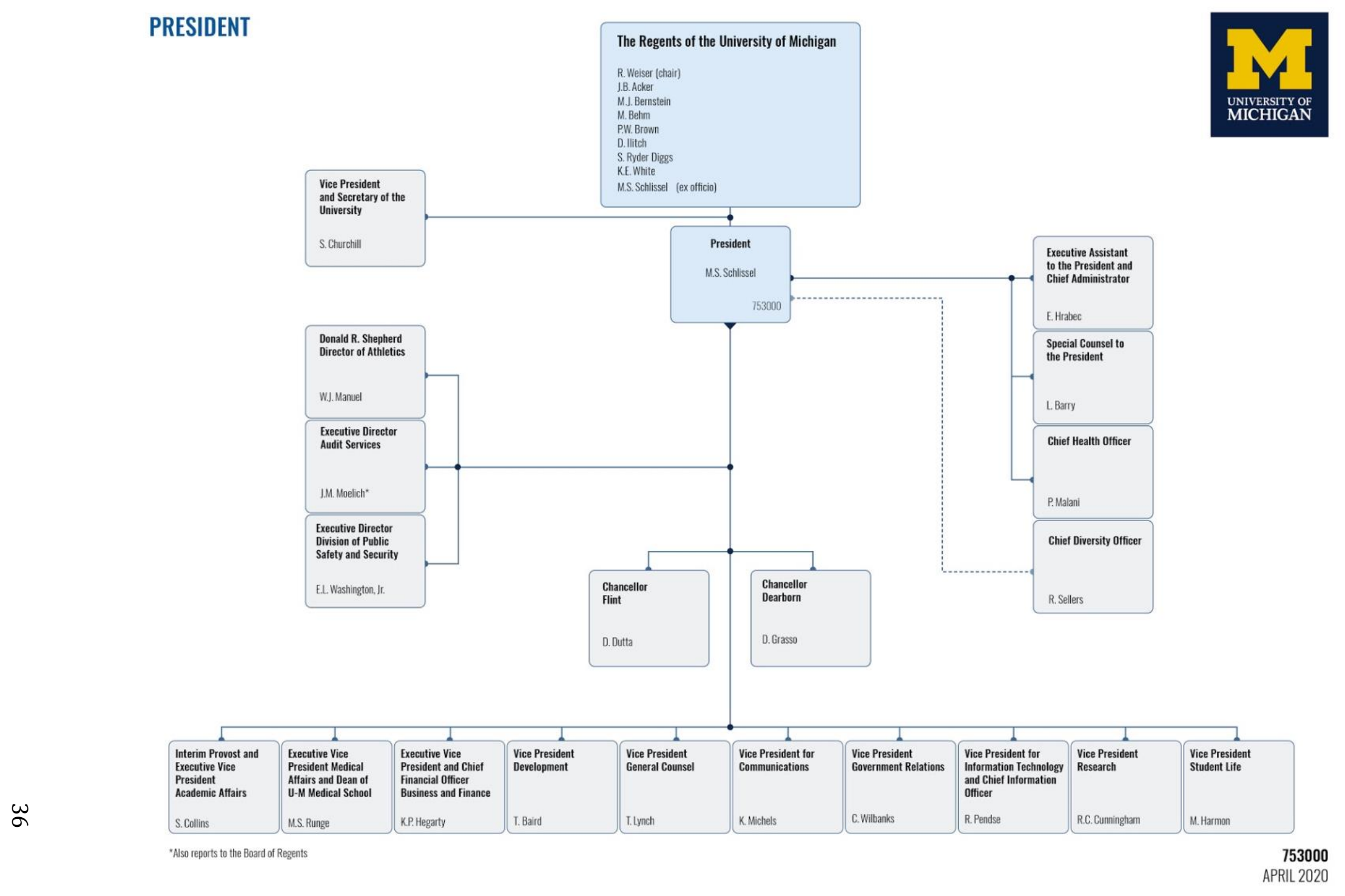


ACADEMIC AFFAIRS

PROVOST AND EXECUTIVE VICE PRESIDENT

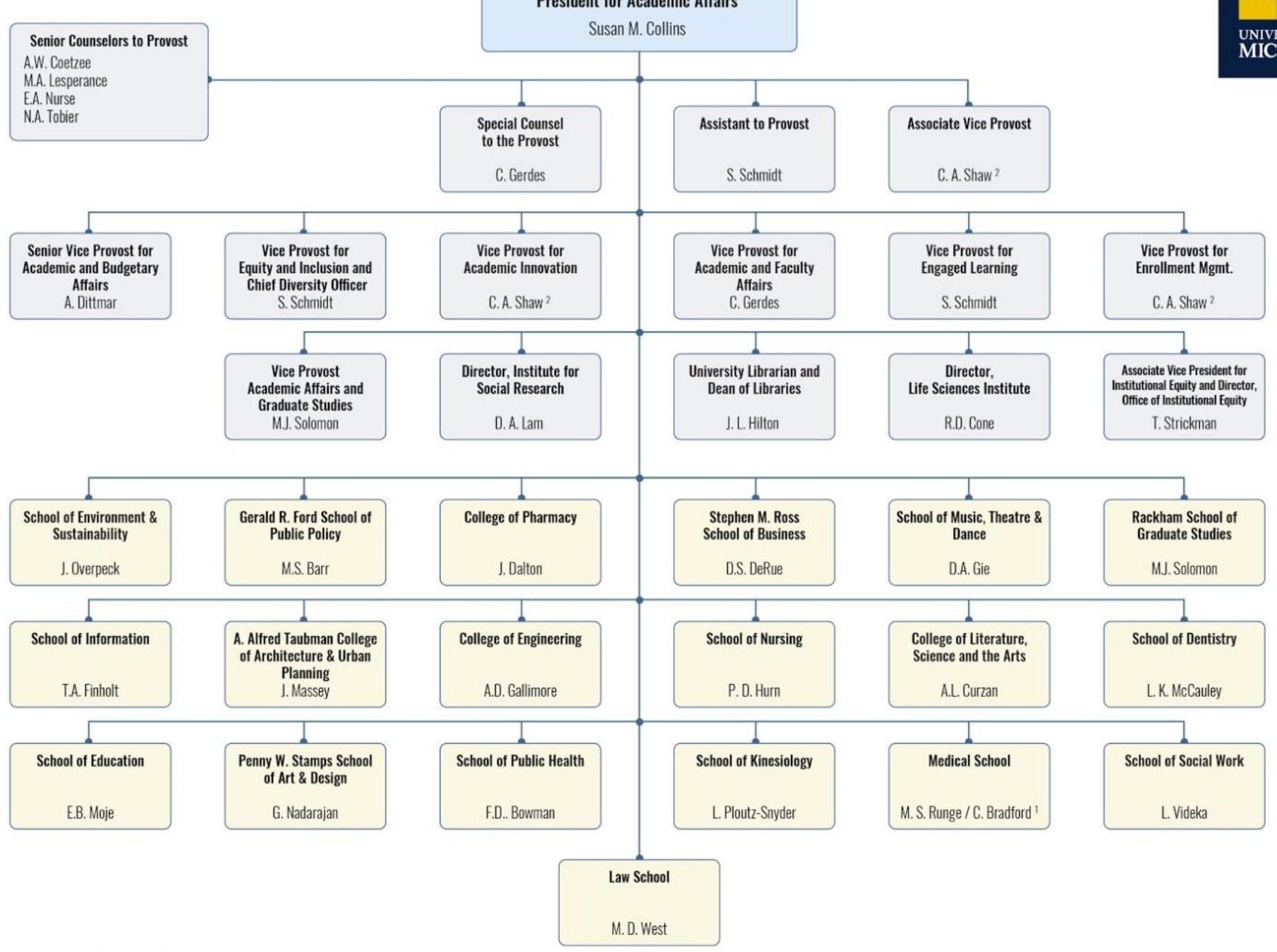




\section{Appendix D: U-M Community Recommendations Matrix}

Via a survey and four town halls we posed the following questions to the U-M community. We worked to faithfully document these ideas. The full database is available at https://docs.google.com/spreadsheets/d/16B60Af3Z9-

vJcx003QUBRIMHOMHXp0XybMiME4QOJas/edit\#gid=0.

- What challenges does the campus face regarding carbon neutrality \& sustainability?

- What concerns do you have regarding campus carbon neutrality \& sustainability?

- What ideas do you have regarding campus carbon neutrality \& sustainability?

- Where do you get and/or would like to get information about campus carbon neutrality \& sustainability?

- What cultural spaces \& events are important to campus carbon neutrality \& sustainability?

- What U-M and/or community organizations are or should be involved in campus carbon neutrality \& sustainability? 


\section{Appendix E: DEI Structure Feedback}

Date: 04/09/2020

Name: Rachel Neimer

Position: DEI Lead

Office/Program: Office of Academic Innovation

Strengths of Current DEI structure:

- ODEI gives units autonomy to develop issues critical to their unit and does not dictate specific policy and practice to units

- This increased flexibility seems to have reduced resistance to adopting DEI programming

Resources provided under DEI model

- Office which is thinking about the systemic changes that must be made at the university

- This helps to guide movement toward a more socially just university (without forcing it)

- Ample resources for DEI projects (not for people to do them)

- These projects are often seen as an additional burden on workload instead of a core part of an individual's job

- This was a bigger problem at the beginning of DEI than it is now

What support is provided by DEI?

- Implementation leads attend monthly meetings designed for community building and sharing initiatives/best practices

- Resources are made available to all DEI leads via MBox

- These are resources that are being used presently, but also in the past

- Helps to build institutional knowledge which is historically a problem at UM due to the highly decentralized nature of the university

- Unit check-ins with ODEl every semester

- Typically 30-60 min

- Useful for information sharing around ODEl's goals for the semester, receiving feedback from ODEl on programming

Weaknesses of current DEI Structure

- Heavily centered around academic units and less focus on administrative/support units

- Framing is a big issue here, recognizing that support/academic units are structured differently and have different priorities than academic units would help with developing programs and unit strategic plans

- Money for projects not people

- PoC and Marginalized people are often called upon to do DEl work and not compensated for their additional efforts

- Seen as an additional burden

- Support units often do not have full time/dedicated staff for DEI work

- Additional burden

Often a double ask on support staff because they build their own strategic plans but help with development of strategic plans for units.

Ex: CRLT built its own strategic plan, but was also asked by multiple academic units to assist with development of the initial unit strategic plan

Barriers to participation

- Not many barriers to participation

- ODEl is very busy so turn around on grants is slow 
Lack of coherent deadlines for grant applications and funding periods increase burden on the office and units

Integration of DEI programming and Sustainability Programming

- Clear link at a global scale how issues around sustainability are also social justice issues harder to see on a local scale

- Ex: OAl works a lot with classroom resources and environments

- Hard to personally envision how they integrate due to lack of knowledge/experience with what sustainability encompasses

Segregation of DEI and Sustainability Programming

- Personal/local connection to the work is not clear

- University Scale change is very easy to see how it ties to social justice

- Some Graduate students felt like DEI programming is paying lip service and not actually accomplishing anything (based on roundtables done by OAI on DEI programming)

- Due to tensions around sustainability at UM students might have very high expectations on what this office will do/accomplish

- OAI has been particularly frustrated by the highly decentralized nature of sustainability work on campus

- Ex: Attempted to get composting bins for the office, did large group training from PBA o composting, never received compost bins

- 2017 effort to understand faculty public engagement and impact found that the largest barrier to public engagement/impact was attempting to create culture change

- Interesting to see where people accept centralization and don't accept centralization

- Ex: University pivot to all online dude to COVID-19

- Lack of central academic unit limited the speed of response, but it was handled by cooperation between decentralized units

- Ex: Could have been very easy to send out an email to all university units with specific instructions for sustainability considerations before campus was shutdown

- ICE plans demonstrate a university's priorities and sustainability considerations are not part of the university-wide ICE plan as evidenced by COVID-19 response 
Appendix F: Student Sustainability Literacy and Competency Pathway

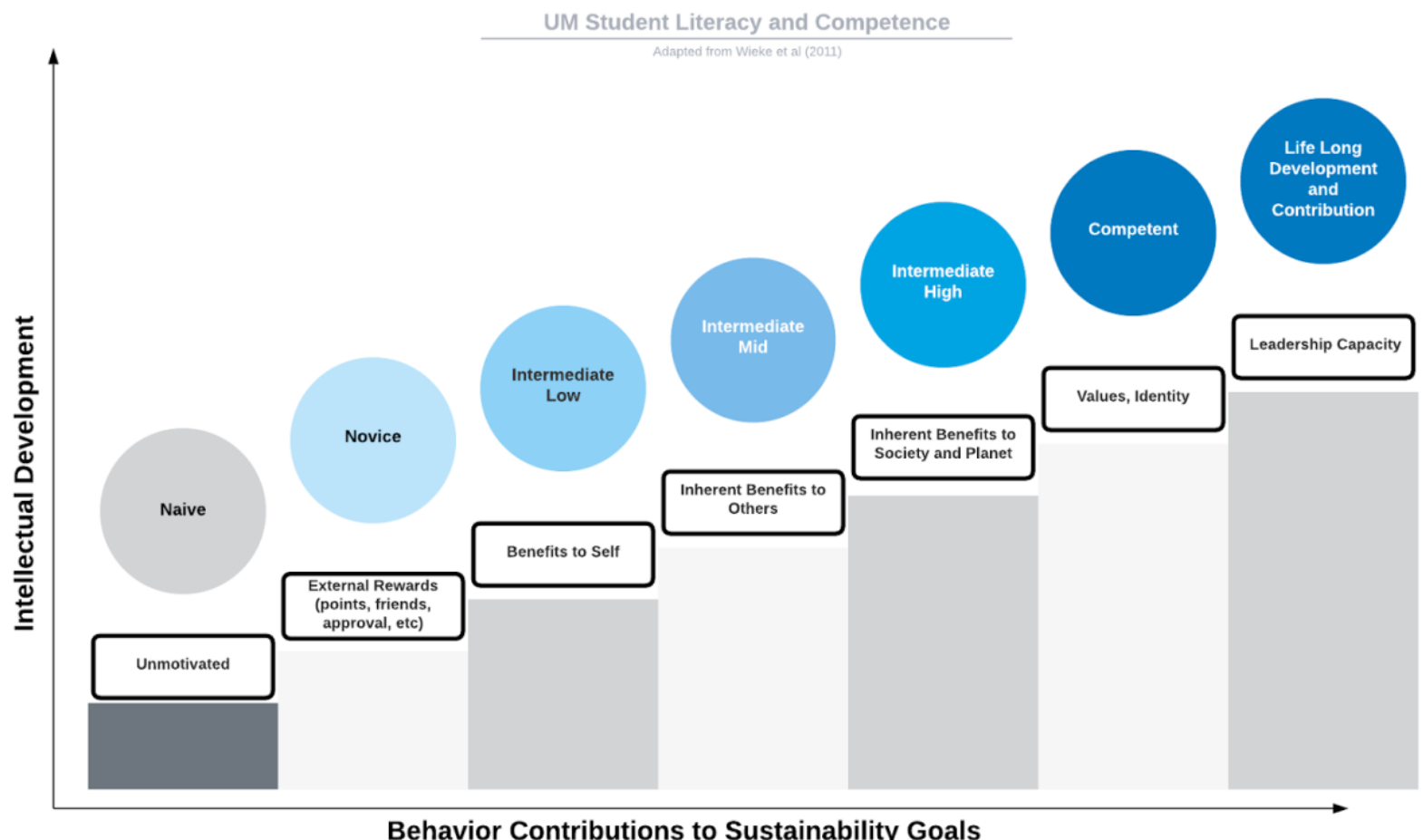




\section{Appendix G: Sustainability Competencies and Course Integration}

Wiek et al. (2011) identify five competencies that define sustainability literacy and integrate across the campus and curriculum for equal access to skills and future opportunities.

1. Systems thinking competency: "the ability to collectively analyze complex systems includes comprehending, empirically verifying, and articulating structure, key components, and dynamics. The capacity to analyze is based on acquired systemic knowledge including concepts such as structure, function, cause-effect relations, but also perceptions, motives, decisions, and regulations; peer-reviewed "classics" such as the Millennium Ecosystem Assessment report (MEA 2005); as well as methods and methodologies such as qualitative and quantitative modeling (Wiek et al. 2011, 207).

2. Anticipatory Competence: "the ability to collectively analyze, evaluate, and craft rich "pictures" of the future related to sustainability issues and sustainability problem-solving frameworks. The capacities to analyze, evaluate, and craft are based on acquired futureoriented knowledge including concepts such as time and uncertainty, peer-reviewed "classics" such as the IPCC's emission scenarios; as well as methods and methodologies such as simulation and scenario analysis" (Wiek et al. 2011, 207-209).

3. Normative Competence: "the ability to collectively map, specify, apply, reconcile, and negotiate sustainability values, principles, goals, and targets. This capacity enables, first, to collectively assess the (un-)sustainability of current and/or future states of socialecological systems and, second, to collectively create and craft sustainability visions for these systems. This capacity is based on acquired normative knowledge including concepts of justice, equity, social-ecological integrity, and ethics (e.g., to know which practices can be transformed or discarded and which must be maintained to sustain viability of life-supporting systems); peer-reviewed "classics" such as the "Brundtland Report" (World Commission on Environment and Development 1987); as well as methods and methodologies such as multi-criteria assessment and structured visioning" (Wiek et al. 2011, 209-210).

4. Strategic Competence: "the ability to collectively design and implement interventions, transitions, and transformative governance strategies toward sustainability. This capacity requires an intimate understanding of strategic concepts such as intentionality, systemic inertia, path dependencies, barriers, carriers, alliances etc.; knowledge about viability, feasibility, effectiveness, efficiency of systemic interventions as well as potential of unintended consequences; peer-reviewed "classics" such as Lester Brown's "Plan B 3.0" (Brown 2008); as well as methods and methodologies of designing, testing, implementing, evaluating, and adapting policies, programs, and action plans, involving different societal actors, facilitating varying perspectives, and acknowledging inconclusive evidence. In simple terms, this competence is about being able to "get things done." This involves familiarity with real-world situations and relationships, political understanding, challenging positions at the right time, being able to solve logistical problems, using language that non-academics are comfortable with, working with deadlines that governments insist on, and so forth" (Wiek et al. 2011, 210-211).

5. Interpersonal Competence: "Interpersonal competence is the ability to motivate, enable, and facilitate collaborative and participatory sustainability research and problem solving. This capacity includes advanced skills in communicating (Crofton 2000; Byrne 2000), deliberating and negotiating (Sipos et al. 2008), collaborating (de Haan 2006; Sterling and Thomas 2006), leadership (Kevany 2007; Ospina 2000), pluralistic and trans-cultural thinking (de Haan 2006; Kelly 2006; McKeown and Hopkins 2003; van 
Dam-Mieras et al. 2008), and empathy (de Haan 2006; Sterling and Thomas 2006). All of these skills are particularly important for successful stakeholder collaboration and a necessity for the majority of methods assigned to previous competencies. The capacity to understand, embrace, and facilitate diversity across cultures, social groups, communities, and individuals is recognized as a key component of this competence" (Wiek et al. 2011, 211). 


\section{Appendix H: Peer Institution Benchmarking}

Available at

https://docs.google.com/spreadsheets/d/1jlwn1sY93iZs Jt5ljug0mUdApeOfn6ozrb GkJ3os/edit\#gid=0

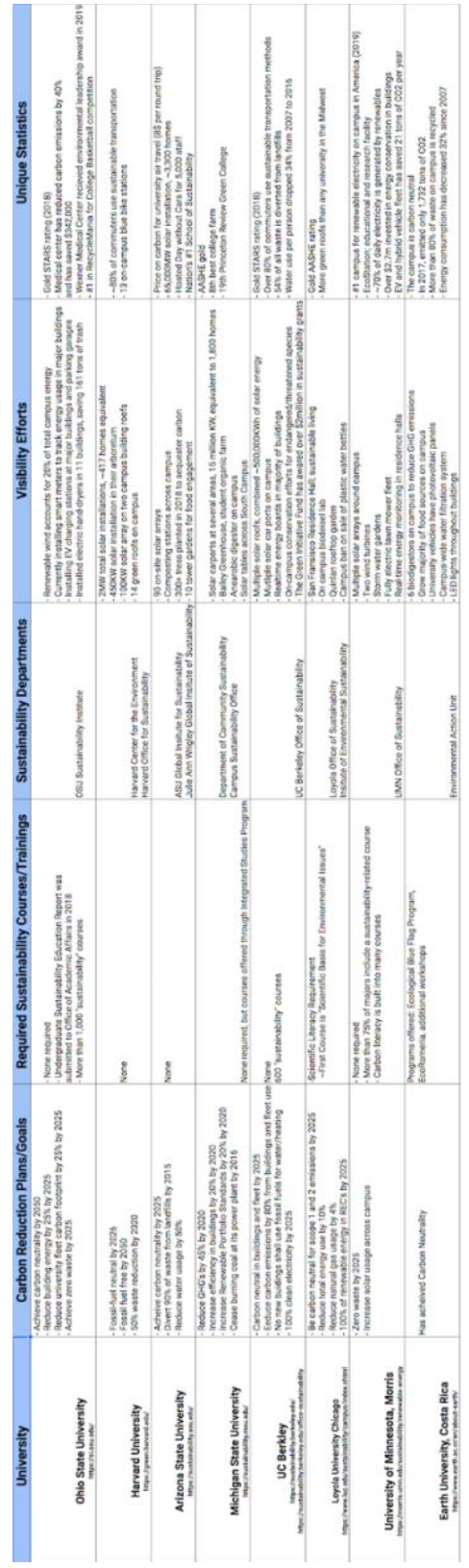




\section{Appendix I: Team Biographies}

\section{Faculty Co-chairs \\ Samer Ali}

Samer is a humanities educator and scholar with expertise in Middle Eastern studies, particularly Arabic poetry. He is currently Associate Professor of Arabic and Islamic culture and Director of the Center for Middle Eastern \& North African Studies at the University of Michigan. Samer writes and lectures on love, learning, and social life in Arabic and Islamic cultures, and his publications include Arabic Literary Salons in the Islamic Middle Ages. He is currently completing a book titled Adab Humanities in Tenth-Century Iraq.

\section{Joseph Trumpey}

Trumpey is a transition designer, science illustrator, educator, and farmer. He holds appointments at the Stamps School of Art \& Design, Program in the Environment, and School for the Environment and Sustainability. Joe directs U-M's Sustainable Living Experience, a living/learning community for first-year undergraduates. He has expertise in sustainable designbuild work, community-based co-design work, and as an illustrator. He has published thousands of illustrations and lectures widely. He and his family live off of the electrical grid in a straw bale home he designed and built in Grass Lake, Michigan. They haven't burned a gram of fossil fuel to heat their home or their water or cook their food in more than a decade of Michigan winters. They farm heritage breed livestock and grow more than half of their annual food.

\section{Student Researchers}

Megan Czerwinski

Meg is a registered nurse and PhD candidate at the University of Michigan School of Nursing. She completed Bachelor's degrees in Art \& Design and Nursing at the University of Michigan. Her dissertation research explores the development of sustainability competence in nurses. Her background includes training environmental education as well as interdisciplinary collaboration to organize a community-sustainability-solutions exchange at the Albert Schweitzer Hospital in Lambaréné, Gabon. She regularly contributes to It's Hot in Here, the environmental radio show on WCBN Ann Arbor, the University of Michigan student-run station.

\section{Benjamin Ingall}

Benjamin is a third-year undergraduate student studying Program in the Environment and Creative Writing. Though he focuses his course work on conservation biology, he has done previous work with the Planet Blue Student Leaders and LSA Recruitment through the Transfer Student Ambassadors on campus. He is also a part of Epsilon Eta, a professional environmental fraternity, and is very passionate about improving the culture around sustainability.

\section{Lisa Maillard}

Lisa is a master's student at the School for Environment and Sustainability in the Behavior, Education and Communication track. She obtained her Bachelor of Arts in Environmental Studies and Global Studies from the University of California, Santa Barbara. She has worked in the field of climate communication and behavior through undergraduate work with the Environmental Humanities Initiative at UCSB and graduate research with the Great Lakes Integrated Sciences and Assessments as well as with Dr. Victoria Campbell-Arvai at the University of Michigan. 
Christopher Merchant

Christopher is a master's student in the School for Environment and Sustainability studying in the Sustainable Systems Track. He has also received a Bachelor of Science in Environmental Studies and Sustainability from Michigan State University. He has prior experience with working toward cultural changes at both an activist level through engagement with extracurricular organizations at prior universities as well as administrative experience through work with the Michigan Department of Environmental Quality and Michigan Farmers Market Association.

\section{Madeline Peery}

Madeline is a third-year undergraduate studying Program in the Environment with a concentration in Environmental Policy. She is a member of Students for Clean Energy and Epsilon Eta professional environmental fraternity, and is most passionate about policy change regarding environmental issues. She has previous experience through work with the Michigan Department of Environment, Great Lakes, and Energy, and has been active in U-M's carbon neutrality mission through student engagement and activism. 


\section{References}

Adams, Richard, Stephen Martin, and Katy Boom. "University Culture and Sustainability: Designing and Implementing an Enabling Framework." Journal of Cleaner Production 171 (2018): 434-445. https://doi.org/10.1016/j.jclepro.2017.10.032.

Agrawal, Arun, Bilal Butt, Maria Carmen Lemos, and Pamela Jagger. "Beyond the Sustainable Development Goals (SDGs): Addressing Sustainability and Development." University of Michigan Coursera Course, 2020. https://www.coursera.org/learn/beyond-thesustainable-development-goals-addressing-sustainability-and-development.

Association for the Advancement of Sustainability in Higher Education (AASHE). "STARS Benchmarking Tool: Academics, Engagement, Innovation \& Leadership Scores." https://benchmarks.aashe.org/\#dashboard. Available at https://drive.google.com/drive/folders/0AHsBxK75FG7cUk9PVA.

Brown, Lester R. Plan B 3.0: Mobilizing to Save Civilization. New York: Norton, 2008.

Brundiers, Katja, and Arnim Wiek. "Do We Teach What We Preach? An International Comparison of Problem- and Project-Based Learning Courses in Sustainability." Sustainability 5, no. 4 (2013): 1725-1746. https://doi.org/10.3390/su5041725.

Byrne, Jack. "From Policy to Practice: Creating Education for a Sustainable Future: A Paradigm of Hope for the 21st Century." In Education for a Sustainable Future, edited by Keith A. Wheeler \& Anne P. Bijur, pp. 35-72. New York: Kluwer/Plenum, 2000.

Carlson, Scott. "How the Coronavirus Tests Higher Ed's Disciplinary Fault Lines." The Chronicle of Higher Education, March 24, 2020. https://www.chronicle.com/article/How-theCoronavirus-Tests/248321/?cid=SLFEED.

Crofton, Fiona S. "Educating for Sustainability: Opportunities in Undergraduate Engineering." Journal of Cleaner Production 8, no. 5 (2000): 397-405.

Czerwinski, Megan. "A Dissertation on Sustainability Competence: Directions for Nursing." PhD diss., University of Michigan, 2020 (undergoing final revisions).

de Haan, Gerhard. "The BLK '21' Programme in Germany: A 'Gestaltungskompetenz'-Based Model for Education for Sustainable Development." Environmental Education Research 12, no. 1 (2006): 19-32.

Devereaux, Brad. "Kalamazoo River Oil Spill Timeline after 6 Years, Billion-Plus Dollars Spent." MLive, July 21, 2016, https://www.mlive.com/news/2016/07/kalamazoo river oil spill time.html.

Duffy, Meghan. Conversation with University of Michigan, Ann Arbor, Biology 171 Professor. 2020.

Durr, Matt. "Property Contaminated with Uranium, Used during WWII Collapses into Detroit River." MLive, December 9, 2019. https://www.mlive.com/news/2019/12/propertycontaminated-with-uranium-used-during-wwii-collapses-into-detroit-river.html.

Eyal, Nir. Hooked: How to Build Habit-Forming Products. New York: Penguin, 2014.

Floyd, André, and Tracy Fernandez Rysavy. "People of Color Are on the Front Lines of the Climate Crisis." Green America. Accessed April 18, 2020.

https://www.greenamerica.org/climate-justice-all/people-color-are-front-lines-climatecrisis.

Gala Platform. University of Michigan School for Environment \& Sustainability, The Regents of the University of Michigan, 2020. Accessed March 9, 2020. https://www.learngala.com/.

Gardner, Paula. "Michigan Hunting for Sources of PFAS in Saginaw River." MLive, January 27, 2020. https://www.mlive.com/news/2020/01/michigan-hunting-for-sources-of-pfas-insaginaw-river.html. 
Glasser, Harold, and Jamie Hirsh. "Toward the Development of Robust Learning for Sustainability Core Competencies." Sustainability: The Journal of Record 9, no. 3 (2016): 121-134. https://doi.org/10.1089/SUS.2016.29054.hg.

Gifford, Robert. "The Dragons of Inaction: Psychological Barriers That Limit Climate Change Mitigation and Adaptation." American Psychologist, Psychology and Global Climate Change 66, no. 4 (May 2011): 290-302. https://doi.org/10.1037/a0023566.

Golrokhian, Arman, Katherine Browne, Rebecca Hardin, Arun Agrawal, Kelly Askew, Laura Beny, Benjamin Larroquette, and Benjamin Morse. "A National Adaptation Programme of Action: Ethiopia's Response to Climate Change." World Development Perspectives 1 (March 2016): 53-57.

Governance \& Accountability Institute, Inc. "Flash Report: $86 \%$ of S\&P 500 Index® Companies Publish Sustainability / Responsibility Reports in 2018." May 16, 2019. https://www.gainstitute.com/press-releases/article/flash-report-86-of-sp-500-indexR-companies-publishsustainability-responsibility-reports-in-20.html.

Grace, Ashlee. "2010-2011 U-M Campus Sustainability Integrated Assessment.” December 12, 2012. http://graham.umich.edu/media/files/CSIA-Evaluation-Report.pdf.

Greenfield, Patrick, and Jonathan Watts. "JP Morgan Economists Warn Climate Crisis Is Threat to Human Race.” The Guardian, February 21, 2020, sec. Environment.

https://www.theguardian.com/environment/2020/feb/21/jp-morgan-economists-warnclimate-crisis-threat-human-race.

Kanter, Rosabeth Moss. "The Change Wheel Elements of Systemic Change and How to Get Change Rolling." Harvard Business Publishing Education, 2011. https://hbsp.harvard.edu/product/312083-PDF-ENG.

Hardin, Rebecca, Anil Bhargava, Cameron Bothner, Katherine Browne, Stephanie Kusano, Arman Golrokhian, Mary Wright, Pearl Zhu Zeng, and Arun Agrawal. "Towards a Revolution in Sustainability Education: Vision, Architecture, and Assessment in a CaseBased Approach." World Development Perspectives 1 (March 2016): 58-63. https://doi.org/10.1016/j.wdp.2016.05.006.

Horhota, Michelle, Jenni Asman, Jeanine P. Stratton, and Angela C. Halfacre. "Identifying Behavioral Barriers to Campus Sustainability." International Journal of Sustainability in Higher Education 15, no. 3 (July 2014): 343-358. https://doi.org/10.1108/ijshe-07-20120065.

James, Matthew, and Karen Card. "Factors Contributing to Institutions Achieving Environmental Sustainability." International Journal of Sustainability in Higher Education 13, no. 2 (June 2012): 166-176. https://doi.org/10.1108/14676371211211845.

Jones, Kelly, and Emily Spillman. "Planet Blue Ambassadors Program Annual Survey Results." 2020. http://sustainability.umich.edu/pba.

Kanter, Rosabeth Moss. "The Change Wheel: Elements of Systemic Change and How to Get Change Rolling." Harvard Business Publishing Education, 2011. https://hbsp.harvard.edu/product/312083-PDF-ENG.

Kelly, Patricia. "Letter from the Oasis: Helping Engineering Students to Become Sustainability Professionals." Futures 38 (2006): 696-707.

Kevany, Kathleen D. "Building the Requisite Capacity for Stewardship and Sustainable Development." International Journal of Sustainability in Higher Education 8, no. 2 (2007): 107-122. https://doi.org/10.1108/14676370710726580.

Levy, Brett L. M., and Robert W. Marans. "Towards a Campus Culture of Environmental Sustainability." International Journal of Sustainability in Higher Education 13, no. 4 (2012): 365-377. https://doi.org/10.1108/14676371211262317. 
Marans, Robert W., John Callewaert, and Noah Webster. "Sustainability Culture Indicators Program (SCIP): Monitoring the Culture of Sustainability at the University of Michigan: Winter 2018." Graham Sustainability Institute Report, 1-130, December 2018. http://graham.umich.edu/media/files/SCIP-Year-5-Report.pdf.

McKeown, Rosalyn, and Charles Hopkins. "EE $\neq$ ESD: Defusing the Worry." Environmental Education Research 9, no. 1 (2003): 117-128. https://doi.org/10.1080/13504620303469.

Millenium Ecosystem Assessment (MEA). Ecosystems and Human Well-Being. Millennium Ecosystem Assessment, 3 vols. Washington, DC: Island Press, 2005.

Ospina, Gustavo López. "Education for Sustainable Development: A Local and International Challenge." Prospects 30, no. 1 (2000): 31-40.

Planet Blue Ambassadors Program at the University of Michigan Planet Blue, The Regents of the University of Michigan, 2020. Accessed March 11, 2020. http://sustainability.umich.edu/pba.

Prushinskaya, Anna, Allen Burton, and Rita Loch-Caruso. "Dioxane Plume Pollution: Who Should Deal with the Groundwater Contamination in a University Town?" Gala. https://www.learngala.com/cases/dioxane-plume.

Remington-Doucette, Sonya, and Sheryl Musgrove. "Variation in Sustainability Competency Development According to Age, Gender, and Disciplinary Affiliation." International Journal of Sustainability in Higher Education 16, no. 4 (2015): 537-575. https://doi.org/10.1108/IJSHE-01-2013-0005.

Rysavy, Tracy Fernandez, and André Floyd. "People of Color Are on the Front Lines of the Climate Crisis." Green America. Accessed April 18, 2020. https://www.greenamerica.org/climate-justice-all/people-color-are-front-lines-climatecrisis.

Schmidt, Aaron, and Amanda Etches. Useful, Usable, Desirable: Applying User Experience Design. Atlanta: American Library Association, 2014.

Shriberg, Michael P. "Sustainability in US Higher Education: Organizational Factors Influencing Campus Environmental Performance and Leadership." International Journal of Sustainability in Higher Education 4, no. 1 (2003). https://doi.org/10.1108/ijshe.2003.24904aae.007.

Sipos, Yona, Bryce Battishe, and Kurt Grimm. "Achieving Transformative Sustainability Learning: Engaging Heads, Hands and Heart." International Journal of Sustainability in Higher Education 9, no. 1 (2008): 68-86.

Sterling, Stephen, and lan Thomas. "Education for Sustainability: The Role of Capabilities in Guiding University Curricula." International Journal of Innovation in Sustainable Development 1, no. 4 (2006): 349-370.

Sustainability Cultural Indicators Program at the University of Michigan Graham Sustainability Institute, The Regents of the University of Michigan, 2020. Accessed February 26, 2020. http://graham.umich.edu/campus/scip/materials.

Thaler, Richard H., and Cass R. Sunstein. Nudge: Improving Decisions about Health, Wealth, and Happiness. New Haven, CT: Yale University Press, 2008.

U-M Committee on the Culture of Sustainability. "2015 Report for President Schlissel from the Committee on the Culture of Sustainability at the University of Michigan." Accessed April 18, 2020. http://sustainability.umich.edu/media/files/Sustainability-Culture-CommitteeReport-2015.pdf.

U-M Greenhouse Gas Reduction Committee. “July 2015 Report from the President's Greenhouse Gas Reduction Committee.” Accessed April 20, 2020. 
http://sustainability.umich.edu/media/files/Greenhouse-Gas-Reduction-CommitteeReport-2015.pdf.

University of Michigan-Ann Arbor and Facilities and Operations. "Five-Year Master Plan University of Michigan-Ann Arbor FY2020." Accessed April 20, 2020.

https://umaec.umich.edu/wp-content/uploads/2018/10/UMAA-FY20-Capital-Outlay-andProject-Request-.pdf.

van Dam-Mieras, Rietje, Angelique Lansu, Marco Rieckmann, and Gerd Michelsen.

"Development of an Interdisciplinary Intercultural Master's Program in Sustainability: Learning from the Richness of Diversity." Innovations in Higher Education 32, no. 4 (2008): 251-264.

Wiek, Arnim, Michael J. Bernstein, Rider Foley, Matthew Cohen, Nigel Forrest, Christopher Kuzdas, Braden Kay, and Lauren Withycombe Keeler. "Operationalising Competencies in Higher Education for Sustainable Development." In Routledge Handbook of Higher Education for Sustainable Development, edited by Matthias Barth, Gerd Michelsen, Marco Rieckmann, and lan Thomas. London: Routledge, 2015.

Wiek, Arnim, Lauren Withycombe, and Charles L. Redman. "Key Competencies in Sustainability: A Reference Framework for Academic Program Development." Sustainability Science, May 19, 2011, 203-218. https://link-springercom.proxy.lib.umich.edu/article/10.1007/s11625-011-0132-6

World Commission on Environment and Development. "Our Common Future." World Commission on Environment and Development. Oxford: Oxford University Press, 1987. 